\title{
Measuring Global Patenting of Universities and Public Research Institutes
}

\author{
JUAN YANG, INTAN HAMDAN-LIVRAMENTO, BRUNOLE \\ FEUVRE, SACHA WUNSCH-VINCENT, AND HAO ZHOU
}

\subsection{Introduction}

Policymakers increasingly seek to bolster the effectiveness of academic research in fostering innovation. Universities and public research institutes are encouraged to engage with industry partners and spur knowledge transfer from academia to the private sector.

One way of facilitating this knowledge transfer is by patenting research outputs from universities and public research institutes. Patents, plus close engagement between universities and public research institutes and the private sector, are two important factors that make university-industry knowledge transfer successful (Perkmann et al. 2013).

Collaboration between academic organizations and the private sector is not new. Universities and public research institutes played important roles in propelling developments in agriculture, aviation, and the chemical and pharmaceutical sectors as early as the nineteenth century (Mowery et al. 2004; Rosenberg and Steinmueller 2013; WIPO 2015). Academic patenting has also been used by university researchers since the late 1800s (Mercelis et al. 2017).

Since the late 1970s, many countries have changed their legislation and created support mechanisms to encourage interaction between universities and firms, including through knowledge transfer (Graff 2007). In 1980, the United States of America (U.S.) passed the Bayh-Dole Act, landmark legislation which allowed for patenting of research outputs funded by the government. Many European countries followed suit about a decade later (Wright et al. 2008; Van Looy et al. 2011). A direct effect of this type of policy is a rise in academic patenting and licensing activities in universities and public research institutes across the U.S. and in certain European countries. 
Policies that encourage patent protection of government-funded research work are intended to promote the commercialization of university inventions, with the aim of facilitating innovation-led economic growth (So et al. 2008). As a by-product, this type of policy provides an avenue for generating income for universities (Geuna 2001) and tracking patenting by research organizations has become one way of measuring their performance.

This chapter focuses on how to identify patenting activities by universities and public research institutes so as to develop cross-country comparison of academic patenting activities. In particular, it proposes a harmonized approach to capture patent filings for these public research organizations across different countries using patent data filed through the Patent Cooperation Treaty (PCT) as well as national-level patent data compiled using the PATSTAT database.

Using patent filing data from the PCT and PATSTAT, we present a new data set of universities and public research institutes which allows for better insights into how effective university knowledge transfer mechanisms have been, and will potentially help to analyze their research performance. Our objective is to gauge the patenting outputs of these organizations, allowing us to measure the evolution of patenting activity over time, benchmark the performance of public research organizations, and enable cross-country comparisons.

This chapter is organized as follows. The next section focuses on academic patenting, in particular, what the data tell us as well as their limitations, and discusses how academic patenting may or may not have changed the norm of universities and public research institutes. We present our methodology for capturing the patenting activities of universities and public research institutes in the third section. The penultimate section analyzes the results of our work by showcasing the results from using the PCT and PATSTAT databases through cross-country and cross-technology comparisons. The last section concludes with direction for future research.

\subsection{Why Focus on Patenting in Academia?}

Total patent filings at the national level are often used as an indicator of the innovativeness of a certain country. By the same logic, patent filing activities can measure the innovativeness of a university or public research institute. But this is not the complete story.

The availability of patent data from the US Patent and Trademark Office (USPTO) and the European Patent Office (EPO) has contributed 
to a rise in quantitative analyses of academic patenting (Rothaermel et al. 2007). University and public research institutes patent filing activities have been used by decision makers to assess the effectiveness of their knowledge transfer offices (KTOs), whether research projects are close to the technological frontier and inventive, the performance of their research staff, and so on. But it is important to remember that this metric is an imperfect measure of innovativeness.

\subsubsection{What Do Patent Data Tell Us?}

There are many limitations to using patenting data to track the performance of public research organizations. First, patent data say relatively little about whether the patented inventions actually result in innovations. In particular, patented inventions from universities tend to be further from commercialization potential than those in the private sector (Henderson et al. 1998; Sterckx 2011). In this sense, patent data provide a relatively imperfect measure of technological activity. ${ }^{1}$

Second, patents are used by universities and public research institutes in a somewhat different way from private sector patents. In the private sector, patents are generally used to appropriate the firms' returns on investing in innovation. ${ }^{2}$ Universities and public research institutes, by contrast, do not directly commercialize their inventions and instead rely on patents to attract industry counterparts. Thus, patents are used as a signal to indicate the value of the protected invention.

Third, a significant share of inventions originating from research performed at universities or public research institutes - universityinvented patents - are not patented under the organization's name. Depending on their employment contract and applicable laws, academics and researchers working in these organizations may be able to file the patent under their names and may later assign the rights to universities. Others may prefer to file under their own names to start their own companies later. A small percentage of university faculty assign the university invention under firm names only and not under the university's name, contrary to university policies (Thursby et al. 2009).

In our methodology, applicants are classified according to their names only, without considering their employment relationship or address. Therefore, where a natural person is the applicant filing on behalf of an

1 See Khan and Wunsch-Vincent (2011), Chapter 1.1, Box 3.

2 See Chapter 2 of WIPO (2011). 
educational organization, that application would not be classified as belonging to a university. Instead, it is imperative that the first applicant is the university or public research institutes itself in order to be categorized as a university or public research institutes patent.

Last, many methods of capturing academic patenting are based on keyword searches and a list of university names. Lesser-known universities or public research institutes, or even those who file their patent applications using different names, may not be captured. As a result, a sizable share of patents derived from public research is underestimated.

\subsubsection{How Does This Apply to Public Research Organizations?}

Academic patenting is not new (Mercelis et al. 2017). For a long while before laws such as the Bayh-Dole Act came to pass - academics enjoyed the privilege of having the first commercial rights over their inventions (Kelly 2016). Some filed for patents on their research work to ensure control over how their work was used, others to build their reputations.

Before the Bayh-Dole Act in the U.S., there was a low level of knowledge transfer from universities to industry; only 5 percent of government-owned university patents were commercialized (Schacht 2006). One of the main barriers to the transfer was the issue of relinquishing ownership rights. First, there were approximately twenty-six different agency policies governing how results of federally funded research and development (R\&D) would be used. Second, licensing policies in place did not provide the appropriate incentive mechanisms to facilitate knowledge transfer.

Changes in the rules governing university patenting have had an impact on the academic patenting culture. First, there has been a general increase in university patenting (Geuna and Rossi 2011; Thursby and Thursby 2011). Second, academic patenting has increased the probability that researchers and professors will start their own companies (Aldridge and Audretsch 2011; Kenney and Patton 2011). Third, while publishing research work in journals continues to be important, there are noticeable delays in publication (Blumenthal et al. 1997). These changes and more have led many to consider universities now as entrepreneurs, not merely knowledge generators (Grimaldi et al. 2011). 


\subsection{How to Measure Academic Patenting?}

\subsubsection{Data Source}

The most comprehensive patent data available today are the WIPO PCT and EPO PATSTAT (April 2016 edition) data sets. We use these two data sets complementarily because they are able to capture patenting activities worldwide. The difference between them is that PATSTAT compiles national patent data from many countries while the PCT captures patents filed through the international PCT system.

The advantage of using the PCT database is that the information is complete and comparable across countries. Patent applicants who wish to file for patent protection in multiple jurisdictions may use the simplified PCT patent filing system. An applicant may deposit their international patent application directly with WIPO either online or by mailing it in, or through national IP offices that send the application to WIPO later. All PCT member countries are able to use this simplified patent filing system.

However, PCT filing is only a subset of all patenting activities. First, applicants who decide to use the PCT route do so because they are interested in filing in several national patent offices and the PCT system allows for a simplified application process (see Box 3.1). It is generally accepted that patented inventions that have been filed at more than one large IP office are of higher value than those that are filed domestically (Dernis and Khan 2004). In this regard, patent applications under the PCT may be considered of higher value due to the potential to acquire patent rights in multiple jurisdictions.

Second, applicants may use the PCT filing system as a business strategy. Universities and public research institutes that choose the PCT system may do so because of the thirty-month transition time between filing for a patent and national phase entry. Anecdotal evidence suggests that some KTOs in universities prefer using the PCT system because it gives them additional time to find commercialization partners for their university inventions. Other applicants may use the PCT system to assess the likelihood of their invention being patentable (Guellec and van Pottelsberghe de la Potterie 2007).

Third, PCT filing may also reflect universities' and public research institutes' stronger or weaker propensity to file abroad.

These factors point to the drawback of using PCT data - that they may underrepresent the total universe of academic patenting, and may merely reflect the strategic patent filing behavior of different universities and public research institutes. 
BOX 3.1 DEFINING PATENT FAMILY

A patent family is a set of interrelated patent applications filed in one or more offices to protect the same invention. The patent applications in a family are interlinked by one or more of: priority claim, PCT national phase entry, continuation, continuation-in-part, internal priority, and addition or division.

A special subset comprises foreign-oriented patent families - those patent families that have at least one filing office different from the office of the applicant's country of origin. Some foreign-related patent families include only one filing office because applicants may choose to file only with a foreign office. For example, if a Canadian applicant files a patent application directly with the USPTO without having previously filed with the patent office of Canada, that patent family will constitute a foreign-oriented patent family with just one office.

Moreover, there are also cost considerations in filing through national IP offices or through the PCT system. The PCT system is a rational filing method if the applicant intends to file in multiple jurisdictions; if not, the costs of application may outweigh the benefits.

The EPO's PATSTAT database, by contrast, allows us to examine a larger set of university and public research institute patenting activities. The PATSTAT data set comprises patent data from different national IP offices that share their data with the EPO, making it easier to capture universities and public research institutes that choose to apply in a single jurisdiction.

But unlike the PCT filing data, the PATSTAT data set is not always complete. Many IP offices in high-income countries provide their patent data to the EPO; the same cannot be said for less-developed economies. Missing data for some offices and years makes the use of this database to run cross-country analysis challenging.

One way to check PATSTAT country and year coverage is to compare the total counts of patents listed in PATSTAT with information collected by WIPO. WIPO conducts an annual survey of national and regional patent office data on patent applications filed. PATSTAT includes only data on published patent applications. A small discrepancy between the two groups - filed versus published - is to be expected: the former is always larger, since some applications are withdrawn before publication, and there is a time lag between filing and publication. If the difference between the numbers as reported to WIPO and PATSTAT for a particular national IP office is small then we can consider PATSTAT coverage of that country reliable; if the difference is large then the data should be analyzed with caution. 
Table 3.1 Comparison of PATSTAT national patent data coverage for featured countries

\begin{tabular}{|c|c|c|c|}
\hline National IP office & $\begin{array}{l}\text { In } \\
\text { PATSTAT }\end{array}$ & PATSTAT coverage & $\begin{array}{l}\text { Incomplete } \\
\text { information }\end{array}$ \\
\hline Brazil & Yes & Good & $2011-14$ \\
\hline China & Yes & Good & 1984 \\
\hline Germany & Yes & Good & \\
\hline South Africa & Yes & $\begin{array}{l}\text { Mostly good, patchy for } \\
\text { some }\end{array}$ & $\begin{array}{l}1986-9,2008-10, \\
2013-14\end{array}$ \\
\hline Republic of Korea & Yes & $\begin{array}{l}\text { Mostly good, patchy for } \\
\text { some }\end{array}$ & $1985-97$ \\
\hline United Kingdom & Yes & Good & $1980-82$ \\
\hline
\end{tabular}

Source: WIPO Department for Economics and Data Analytics Internal Documents, September 2017

Table 3.1 provides a quick overview of national patent data coverage at PATSTAT for the six countries studied in this book. It compares the number of patent filings at the different jurisdictions as reported to WIPO with the number provided by PATSTAT. For South Africa and the Republic of Korea, there are significant discrepancies between the total number of patents filed as reported to WIPO and PATSTAT. There are many possible explanations for this. National events or even changes in legislation in a country may be reflected in its reported IP data.

\subsubsection{Identifying Public Research Organizations}

Identifying universities and public research institutes using patent data is not straightforward. Due to the differences in the patent data contained in the PCT and PATSTAT databases, we employ similar methods but with a few important variations to capture academic patenting activities.

First, patent documents do not contain standardized information on the applicant type, so we rely on the information contained in the applicant's name or address in developing search algorithms to identify university and public research institute patents.

Using the PCT database, we search the names of applicants or their addresses as recorded in patent documents, and determine whether the applicant is a university, public research institute, company, or individual using certain words, for example, "university," "college," 
"school," "government," and "ministry." We perform this search in various languages to make sure that we also capture organizations in non-English-speaking countries. Moreover, we have a list of universities and public research institutes that we use specifically in the context of PCT filings to help us identify academic patents.

The PATSTAT database provides a table which categorizes applicant types by the following four categories: individuals, private business firms, universities and higher education organizations, and government agencies. ${ }^{3}$ This applicant classification was developed by the Catholic University of Leuven in Belgium, which employed a similar search strategy to ours. ${ }^{4} \mathrm{We}$ use this categorization to target the subcategory of patent applicants that have been classified as "universities and higher education institutions."

Second, name-cleaning is tedious. Applicant names provided in the PCT and PATSTAT are neither standardized nor harmonized, making it challenging to identify universities and public research institutes by either keywords or names. In addition, applicant names and addresses may be in languages other than English and may be written in non-Latin characters.

Ensuring that the list of university and public research institute names captured is representative of the different languages as well as non-Latin characters would require additional lists of keywords or similar name matches. In this respect, the PCT database provides an advantage over PATSTAT. PCT filing requires applicants to provide their names in a standardized English version as well as in the nine other languages accepted. ${ }^{5}$ The applicants' names and addresses have to be indicated in Latin characters, either as transliteration or translation into English. ${ }^{6}$

The national IP data provided for PATSTAT, however, can be in any language, including exotic languages, and the applicants' names and addresses may be listed in non-Latin characters. Accordingly, we employ a WIPO-created list of university and public research institute names and the associated keywords to capture academic applicants that may have been unintentionally omitted by PATSTAT through its applicant type table.

This list was created through direct contact with government officials, and verified by consulting government websites as well as university and public research institute directories. It contains the names of universities

3 This category was developed by the KU Leuven group. See Du Plessis et al. (2010).

${ }^{4}$ See Du Plessis et al. (2010).

${ }^{5}$ Applicants may fill their patent applications in any of the following ten official languages: Arabic, Chinese, English, French, German, Japanese, Korean, Portuguese, Russian, and Spanish.

${ }^{6}$ See Rule 4.16 of the Regulations under the Patent Cooperation Treaty (1970). 
in fifty-four countries and public research institutes in thirty-eight countries. ${ }^{7}$ We mined the list to identify keywords that would help us tag universities and public research institutes in the different languages. We further added to this list the top 200 publishing organizations from sixty-two different countries that we have established using Scopus, a database containing citations and abstracts for scientific journal articles. ${ }^{8}$ And last, we use the Scimago Institutions Rankings World Report (2010) to include the top publishing organizations in the world $-2,833$ in total.

Third, the name-matching processes for academic organizations under PCT and PATSTAT differ due to the volume of data to process. At the last count, PATSTAT covers over 100 million patent documents while the PCT covers 3.5 million patent documents. ${ }^{9}$

For the PCT, once we have identified patents from universities and public research institutes, we manually match all the names that seem similar. In the case of PATSTAT, we focus on the top filers, assign a similarity value based on the similarities of the names, and try to match them. So for example, if we wish to identify the top 100 academic organizations we look at the top 300 filers, find those that are similar and then match them manually.

Fourth, the decision on patent family definition (see Box 3.1) should be tailored to the research question, especially in the case of PATSTAT. ${ }^{10}$ Since PATSTAT provides all available national patent data collection, universities and public research institutes that have filed for patents in multiple jurisdictions for one invention would need to be accounted for

7 The fifty-four countries for which a university list has been compiled are: Argentina, Australia, Austria, Bangladesh, Belgium, Brazil, Bulgaria, Canada, Chile, Colombia, Cuba, Czech Republic, Denmark, Egypt, Estonia, Ethiopia, Finland, France, Germany, Greece, Hungary, Iceland, India, Indonesia, Iran (Islamic Republic of), Ireland, Israel, Italy, Japan, Republic of Korea, Luxembourg, Malaysia, Mexico, Netherlands, New Zealand, Nigeria, Norway, Philippines, Poland, Portugal, Russian Federation, Serbia, Slovakia, Slovenia, South Africa, Spain, Sweden, Switzerland, Turkey, United Kingdom, Ukraine, U.S., Uzbekistan, and Venezuela. The thirty-eight countries for which a public research institute list has been compiled are: Argentina, Australia, Austria, Belgium, Brazil, Canada, Chile, Colombia, Czech Republic, Denmark, Estonia, Ethiopia, Finland, France, Germany, Greece, Hungary, Iceland, Ireland, Israel, Italy, Japan, Republic of Korea, Luxembourg, Mexico, Netherlands, New Zealand, Norway, Poland, Portugal, Slovakia, Slovenia, Spain, Sweden, Switzerland, Turkey, United Kingdom, and the U.S.

8 The Scopus database contains 12,400 organizations in total.

9 Based on PATSTAT Spring 2017 edition and PCT 2017 edition.

${ }^{10}$ See Martínez (2011) for the different patent family types and how they relate to the research question. 
so that we do not double-count those filings. This is not the case for PCT, as it is just a patent-filing method.

For the purposes of this chapter, we define a patent family based on the earliest filing and where all other filings claim this first filing as a priority. In particular, we focus on patent families that are associated with patent applications with inventions and exclude those associated with utility model applications. The benefit of this patent family definition is that it enables us to track where the invention was first filed and where the applicant later sought protection for that particular invention (Martínez 2011).

And last, assigning the origin of the university and public research institute patent is usually done based on the residence - not the nationality - of the first applicant. In the case of PCT data, it is simply the first applicant's residence as noted in the PCT filing document. For PATSTAT, it would be the residence of the first applicant of the first filing for that patent family.

\subsubsection{Quality Checks}

One of the main issues in identifying patent activities by public research organizations is to ensure that we have correctly captured applicants who fall within this category.

When carrying out the strategy of identifying public research organizations, researchers need to ask themselves which problem is worse: including applicants who do not fall under the category of public research organizations (false positive) or excluding those applicants who do fall under the category (false negative)?

Several quality checks have been performed, especially on the method used to extract university and public research institute patents from the PATSTAT database. Two issues emerged: first, whether the data compiled by PATSTAT has good country and time coverage; and, second, whether the search method employed performed well in identifying the academic organizations.

The first question can be addressed by comparing PATSTAT data on aggregate applications per year per country of origin to aggregate numbers reported to WIPO by national and regional patent offices, as we did to produce Table 3.1 above.

To verify how well the search method identifies organizations, we compare the results obtained with government reports for selected countries wherever available. 


\subsection{Who Is Patenting and Where?}

Academic patenting - measured by patent filing activities by universities and public research institutes worldwide - is on the rise. Since 1995, the number of PCT applications filed by universities and public research institutes has been steadily increasing (see Figure 3.1). The growth in PCT applications filed by university and public research institute applicants combined since 1995 can be divided into two periods. In the period 1995-2008, the average annual growth rate in academic patent filings was 13.3 percent. The period 2009-16 saw average annual growth of 2.4 percent in PCT applications, 2.3 percent in university applications and -0.4 percent in public research institute applications. Growth in public research institute and university PCT filings declined during and after the economic downturn of 2009 compared to the previous period of high growth.

Patent filings captured by PATSTAT data also show an increase in academic patenting. Figure 3.2 shows the total number of patent families created by universities and public research institutes. In 2014, about 162,000 patent families were created by university and public research institute applicants worldwide. On average, the total number of university and public research institute patent families (16.5 percent) grew much faster than overall total number of patent families (4.9 percent) over the period from 1995 to 2014 . As a result, the share of university and public research institute patent families in total families has been increasing rapidly - especially for universities - reaching 11.4 percent in 2014, up from 1.5 percent in 1995.

Again, the trend in university and public research institute patent families can be divided into two distinct periods. The period 1995-2004 saw average annual growth of 12.1 percent, with patent families from universities (12.3 percent) and public research institutes (11.8 percent) growing at almost same pace. The period 2005-14 saw even faster growth. The average annual growth rate for this period was 5.4 percent for all families and 19.6 percent for university and public research institute families combined. However, patent families from universities (22.4 percent) grew much more quickly than those from public research institutes (11.3 percent).

The slowdown of the growth in PCT patent filings and the increasingly rapid growth of PATSTAT patent filings seem to contradict one another. However, this is not necessarily the case.

The share of foreign-oriented patent filings by academic organizations has been decreasing. Figure 3.3 shows the number of foreign-oriented patent families created by universities and public research institutes from 1995 to 2013 and the share of foreign-oriented patent families in total patent families for each type of applicant. 


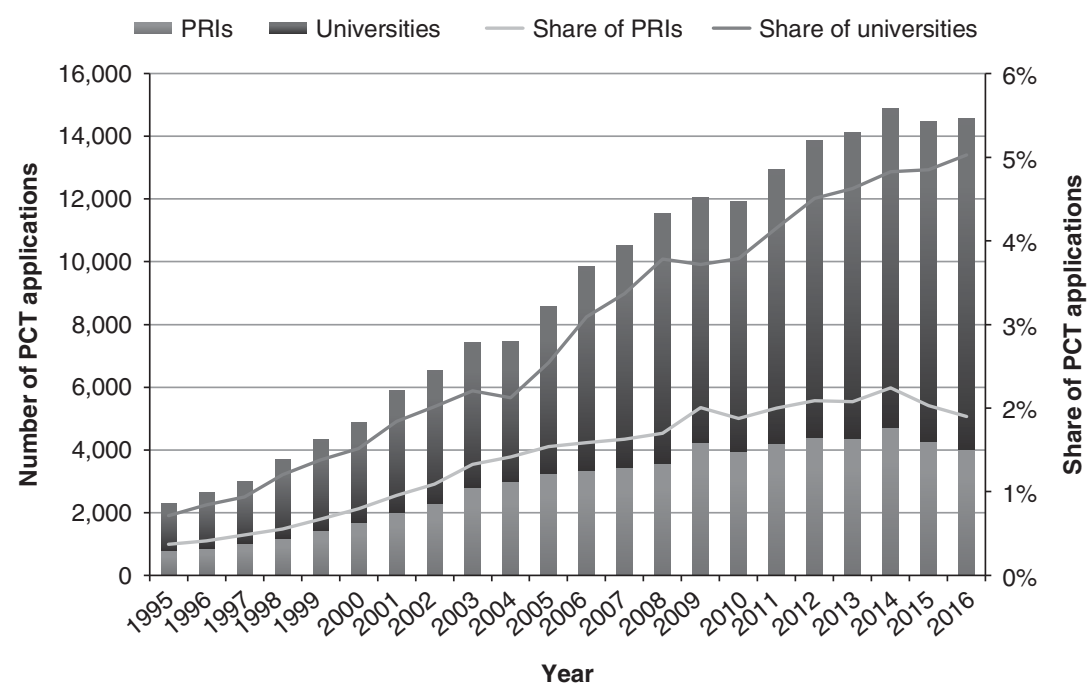

Figure 3.1 Public research institute and university PCT applications, absolute numbers (left) and as a percentage of total PCT applications (right), 1995-2016 Source: WIPO Statistics Database, July 2017

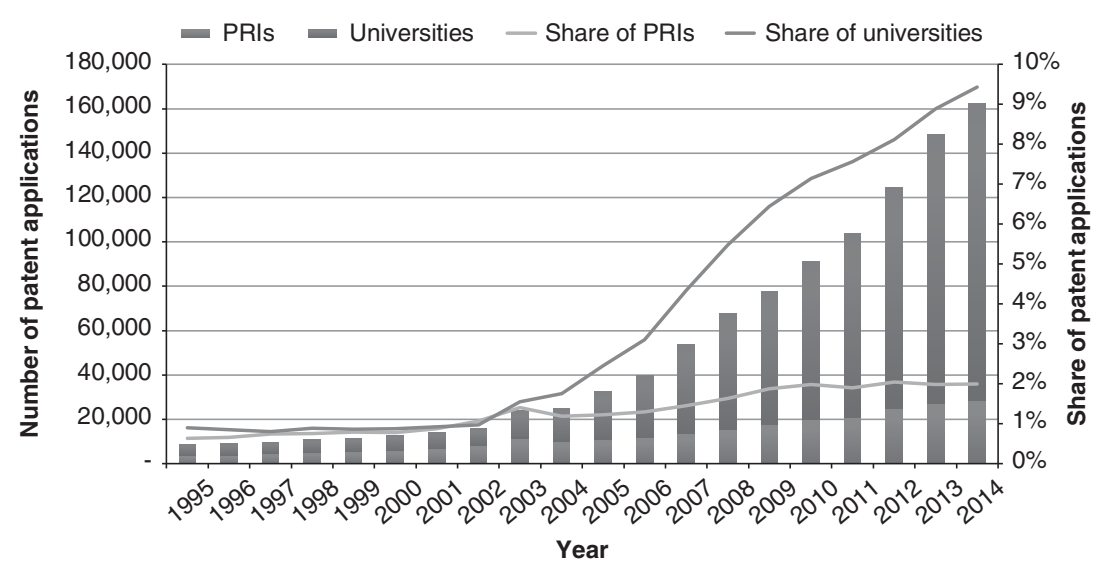

Figure 3.2 Trend and share in university and public research institute patent families worldwide, 1995-2014

Sources: WIPO Statistics Database and EPO PATSTAT database, July 2017 


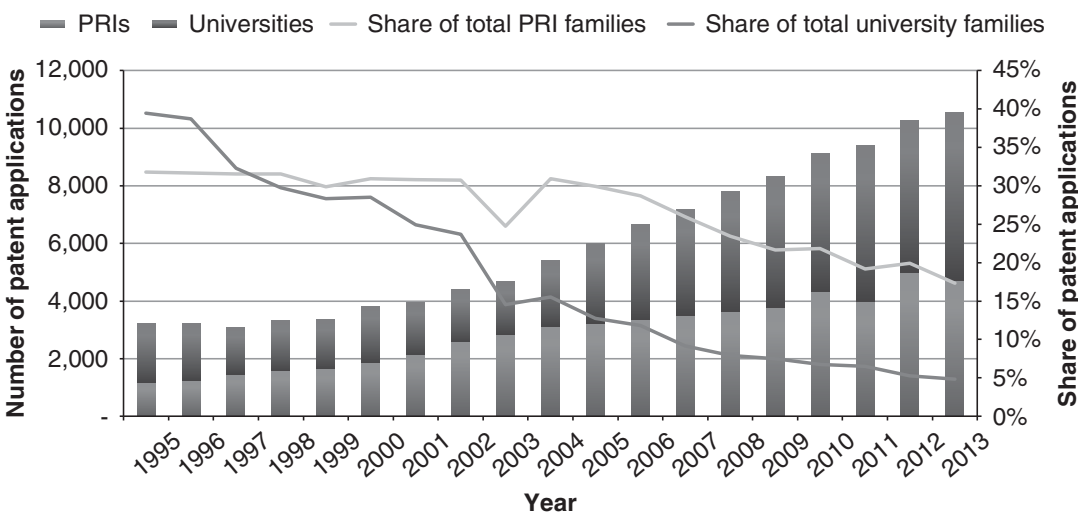

Figure 3.3 Trend in university and public research institute foreign-oriented patent families worldwide and share of total, 1995-2013

Sources: WIPO Statistics Database and EPO PATSTAT database, July 2017

Figure 3.3 shows that while the number of foreign-oriented patent families from universities and public research institutes increased steadily over the past two decades, their respective shares of total patenting activity by those organizations decreased sharply. In 1995, universities created 2,058 foreign-oriented patent families and public research institutes created 1,177. In 2013, universities and public research institutes created three to four times more foreign-oriented patent families $-5,858$ and 4,702, respectively. The combined total of foreign-oriented patent families for universities and public research institutes increased each year between 1998 and 2013 to reach 10,560 in 2013.By way of contrast, the share for universities decreased from 39.5 percent of foreign-oriented patent families in 1995 to 4.8 percent in 2013. This indicates that the number of patent families that have no international dimension is increasing much more rapidly than the number of foreign-oriented patent families.

What explains the drop in foreign-oriented patent filings by universities and public research institutes? That is outside the scope of this chapter. It may indicate a change in academic patenting strategy, with more universities and public research institutes preferring to file in one office rather than several. But it could also be due to the filing strategy of academic organizations of one country: China.

\subsubsection{By Income Level}

In the PCT data, European and US universities and public research institutes have traditionally accounted for the bulk of academic filings 
globally. ${ }^{11}$ These high-income countries accounted for the vast majority of university ( 87 percent) and public research institute ( 80 percent) PCT filings in 2016. US universities accounted for 38 percent of all PCT applications filed by universities in 2016, about 11 percentage points below their 2007 share (Figure 3.4). In the same year, the shares of the top five public research institute origins in total public research institute filings ranged from 19 percent for France to 9 percent for Germany. ${ }^{12}$

However, Asian academic organizations, led by China, have been catching up quickly over the past few decades. The top five origins of university PCT filings in 2016 were the U.S. $(4,050)$, China $(1,169)$, the Republic of Korea $(1,139)$, Japan $(985)$, and the United Kingdom (446). In contrast, the top five origins of university PCT filings in 2007 were the U.S., Japan, France, the United Kingdom, and Germany. The change in top five origin ranking between 2007 and 2016 can be explained by the sharp rise in PCT patent filings from China and the Republic of Korea by 9 and 7 percentage points, respectively.

Shares for the middle-income group increased rapidly between 2007 and 2016, by 10 percentage points for universities and by 13 percentage points for public research institutes (see Figure 3.5). Chinese universities accounted for 83 percent of total middle-income university filings in 2016, while Chinese public research institutes represented 72 percent of total middle-income public research institute filings. The other main middle-income origins in 2016 for universities were South Africa (fortyseven applications), Turkey (thirty-six), India (thirty-three), Malaysia (thirty-two), Colombia (twenty-eight), Brazil (twenty-five), Mexico (nineteen), and Morocco (eighteen); and for public research institutes they were India (132), Malaysia (fifty), South Africa (twelve), Turkey (eleven), and Brazil (nine).

\section{Comparing Academic Patenting in High- and Middle-Income Economies}

Figure 3.6a shows the share of university and public research institute PCT applications in the total number of PCT applications by income group. The shares for high-income countries grew consistently during

11 The country assigned to an application is the country of residence of the first applicant. Data are classified either by origin (all applications with the first applicant originating from that country) or by office (all applications filed in that country).

12 Public research institutes in France filed the most PCT applications in 2016, with 745 PCT filings, followed by China (573), the U.S. (569), the Republic of Korea (491) and Germany (372). 

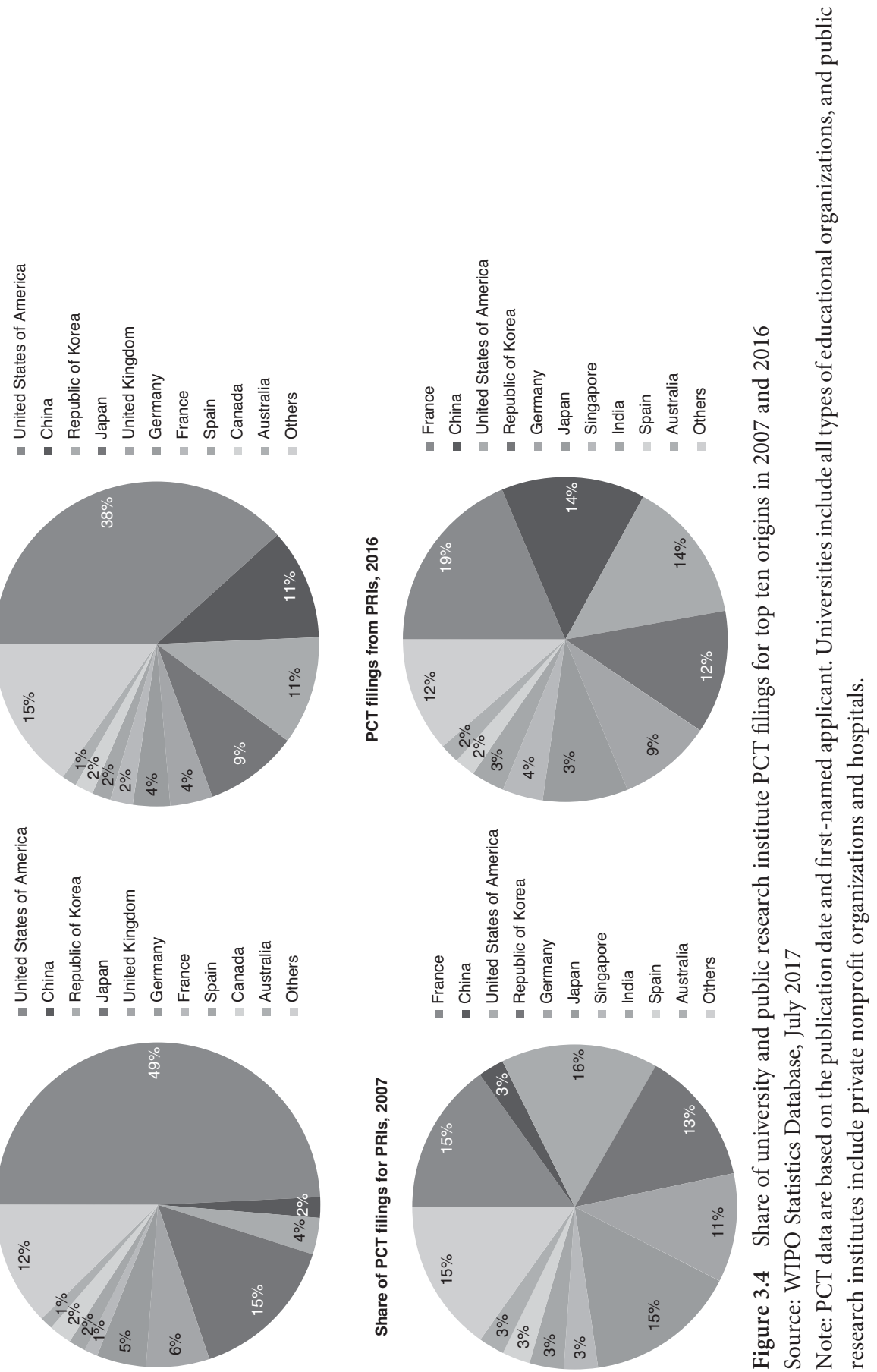


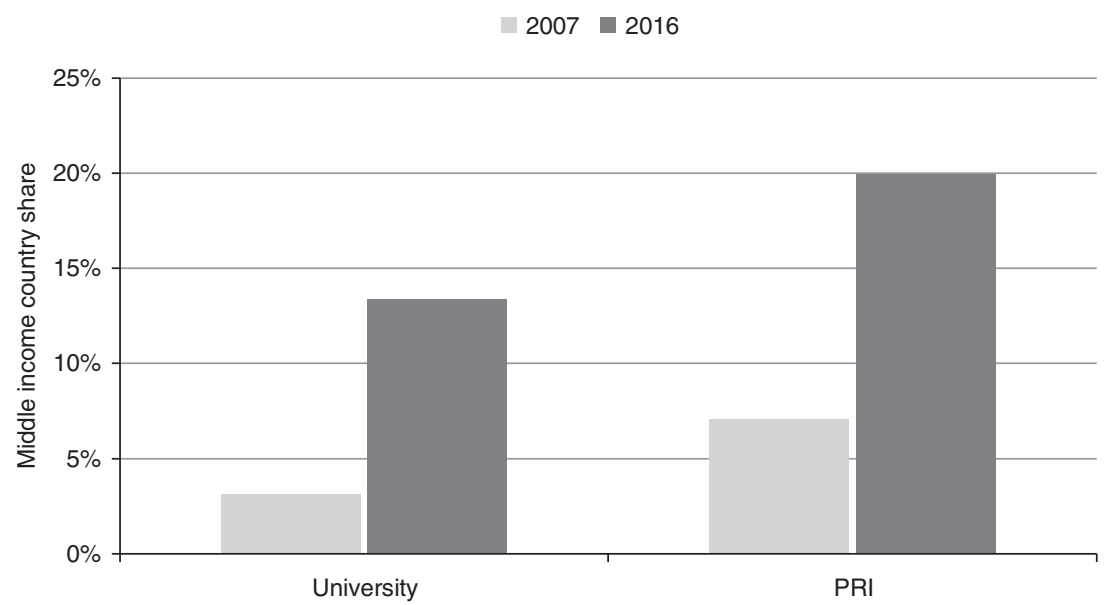

Figure 3.5 University and public research institute PCT filings originating from middle-income countries as a share of total university and public research institute PCT filings

Source: WIPO Statistics Database, July 2017

Note: PCT data are based on the publication date and first-named applicant.

Universities include all types of educational organization, and public research institutes include private nonprofit organizations and hospitals.

the period $1980-2015$, and ranged from 5.1 percent to 8.5 percent. In the period 1980-90, university and public research institute PCT applications from middle-income economies represented just over 2.8 percent of those countries' PCT applications. That share increased dramatically to over 8.0 percent in 1991-2000, and was fairly stable at almost 9.1 percent during the period 2001-15. PCT filings from China could potentially bias the middle-income share due to the high filing activity in that country. However, if China is removed from the count, the share of university and public research institute PCT applications in the total number of PCT applications from middle-income countries actually increases to 10 percent. This shows that universities and public research institutes play an important role in the innovation capability of a number of middle-income economies.

Figure 3.6b depicts the share of university and public research institute patent applications in total patent applications by income group. For high-income economies, this share increased gradually from about 1.2 percent to 5.1 percent between $1980-90$ and 2011-13. Most of this 

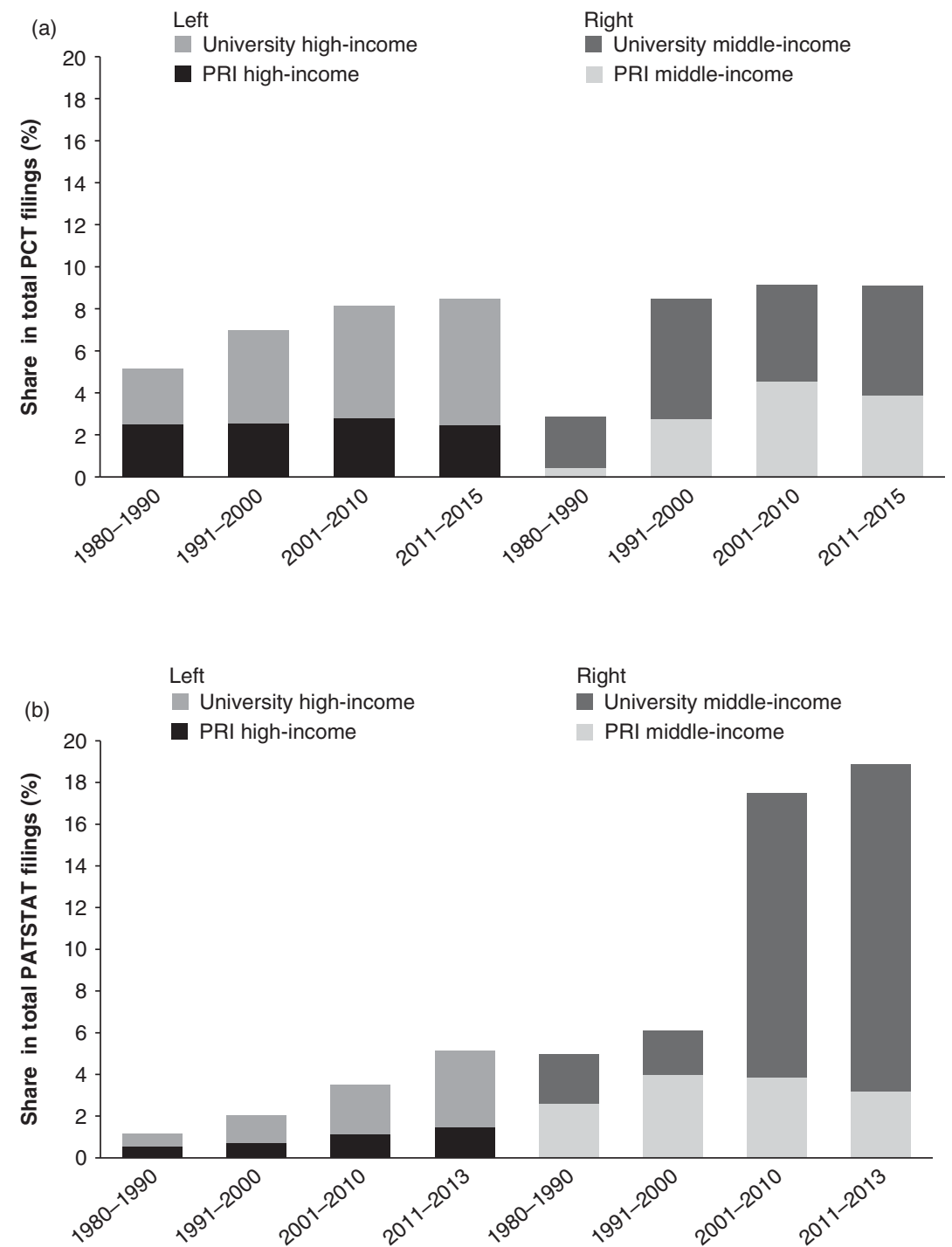

Figure 3.6 Increase in university and public research institute filings by high- and middle-income groups

3.6a Share of university and public research institute filings in total PCT applications by income group (\%), 1980-2015

3.6b Share of university and public research institute applications in total patent applications by income group (\%), 1980-2013

Source: WIPO Statistics Database, April 2016 
increase originated from universities. The share of university and public research institute applications in middle-income countries has exceeded that of high-income economies since 1980, and increased sharply from about 5.0 percent in 1980-90 to nearly 18.9 percent in 2011-13.

Figure 3.7 decomposes the patenting activity for the most active countries over the last decade. As Figure 3.7a shows, in 2004-13 China accounted for slightly less than half (49.0 percent) of all patent applications filed by universities across the world. It was followed by the U.S. (14.0 percent), and the Republic of Korea (11.3 percent). These top three countries combined accounted for nearly three-quarters ( 74.3 percent) of the filings originating from the world's universities.

Filings from public research institutes are less concentrated than those from universities, as shown in Figure 3.7b. Public research institute filings from China (31.2 percent), the Republic of Korea (23.3 percent), and France (12.5 percent) combined accounted for 67.0 percent of total filings -7.3 percentage points below the combined share for the top three countries in university filings (74.3 percent). These shares also reflect a shift in university and public research institute filings from the U.S. and Europe toward Asia.

Figure 3.8 shows the trend over the past decade in PCT filings for selected origins. The key findings can be summarized as follows: US university PCT filings represented about 7.6 percent of total US PCT filings between 2006 and 2015. The number of US university PCT filings remained relatively stable throughout this period, varying between a minimum of 3,560 in 2010 and a maximum of 4,573 in 2014. US public research institute PCT filings accounted for slightly more than 1 percent of total US PCT filings over the past decade and amounted to 753 PCT filings in 2015.

The shares of university and public research institute PCT filings from Germany were also quite stable, each representing between 2 percent and 3 percent of total PCT filings from Germany between 2006 and 2015. For universities, the total number of PCT filings in 2015 was 490 and for public research institutes 456 .

PCT filings by French universities accounted for between 3.2 and 7.5 percent of the country's PCT filings since 2006. The number of PCT filings from French universities increased from 204 in 2006 to 671 in 2015. The share of French public research institute PCT filings was nearly 12 percent in most of the reported years, and their number of PCT filings increased from 646 in 2006 to 1,165 in 2015. 
98 YANG, HAMDAN-LIVRAMENTO LE FEUVRE, WUNSCH-VINCENT, \& ZHOU

(a)

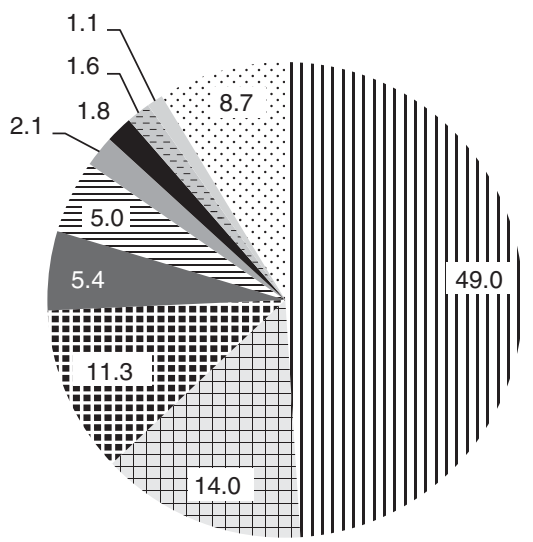

|| China

\pm United States of America

I Republic of Korea

Russia

三Japan

United Kingdom

Germany

France

Poland

$\therefore$ Others

| / China

壮 Republic of Korea

H:Hrance

- Japan

$\equiv$ Germany

United States of America

ロ Singapore

Russia

EIndia

Spain

Others

Figure 3.7 University and public research institute patenting by leading origin countries

3.7a University patent applications in the world for selected countries (\%), 2004-13

3.7b Public research institute patent applications in the world for selected countries (\%), 2004-13

Sources: WIPO Statistics Database and EPO PATSTAT database, April 2016 
As for the share of university PCT filings from the United Kingdom, it tended to increase slightly over time and accounted for 10.3 percent of total UK PCT filings in 2015. The number of PCT filings reached 545 in 2015. The share of UK public research institute PCT filings was 1.1 percent in 2015 and represented only fifty-seven PCT filings.

The share of Japanese university and public research institute PCT filings tended to decrease over time. The share for universities decreased from 5.3 percent in 2006 to 3.1 percent in 2015, while that for public research institutes fell from 2.6 percent to 1.1 percent. These declines are due to a fall in the number of PCT filings originating from Japanese
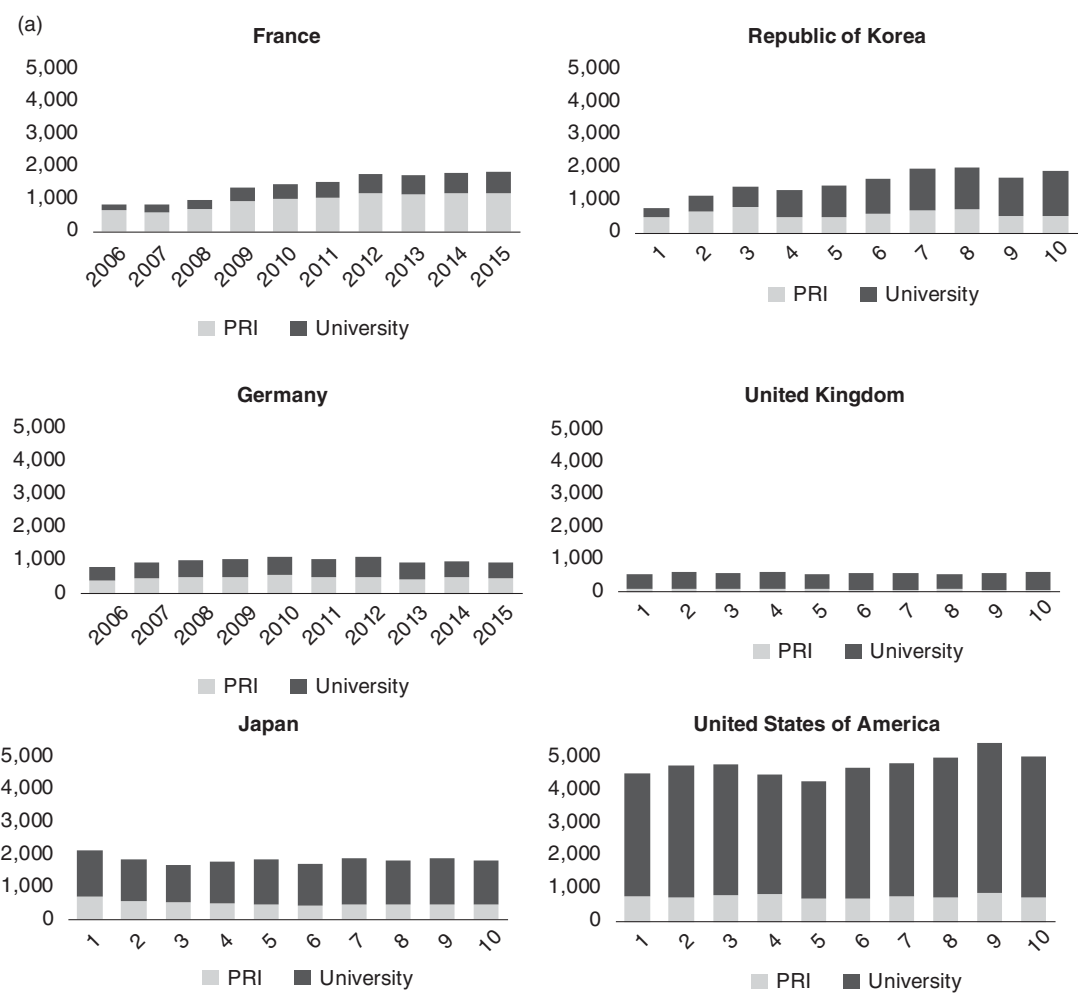

Figure 3.8 The trend over the past decade in PCT filings for selected origins 3.8a Public research institute and university PCT applications from high-income countries, absolute numbers, 2006-15

3.8b Share of public research institute and university PCT applications from highincome countries, country shares (\%), 2006-15

Sources: WIPO Statistics Database and EPO PATSTAT database, April 2016 

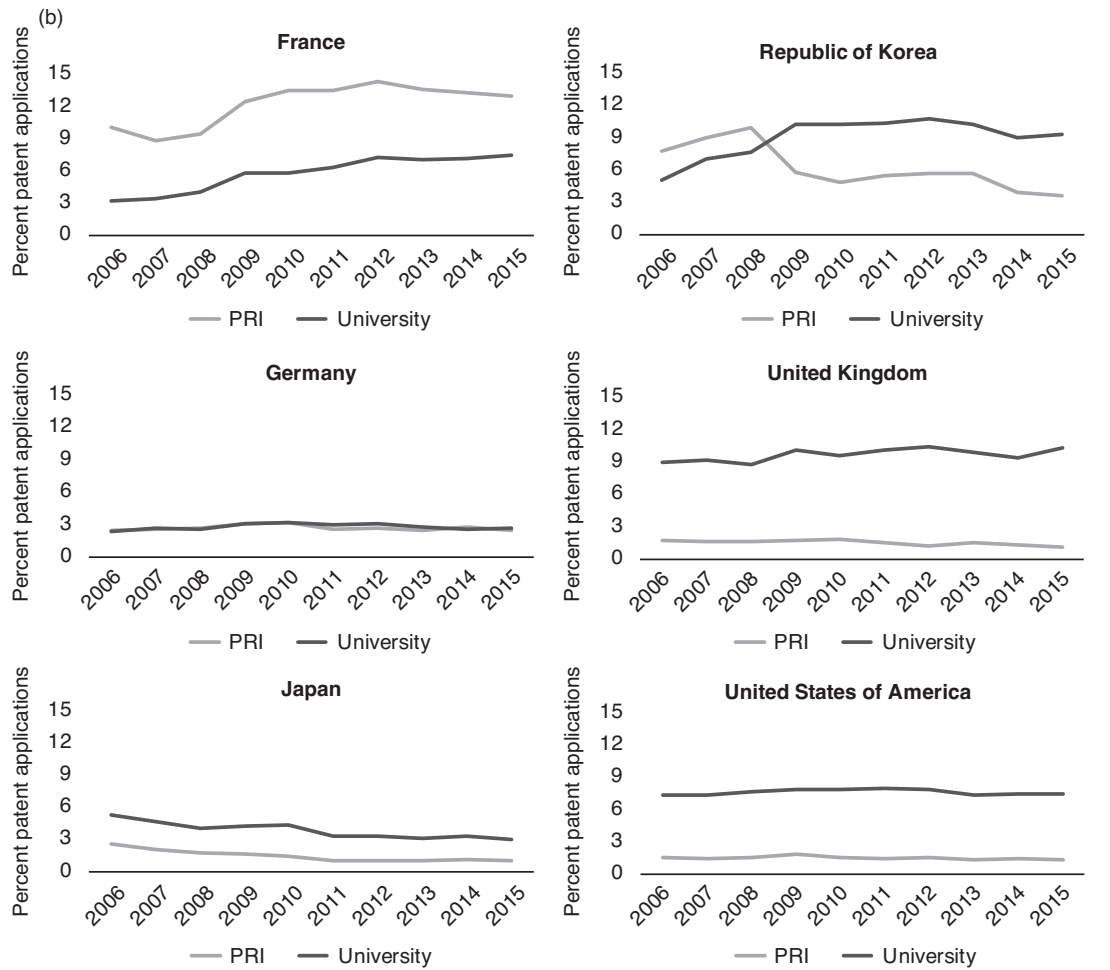

Figure 3.8 (cont.)

universities and public research institutes; in 2015 they filed 1,346 and 480 PCT filings, respectively.

The share of filings from universities in the Republic of Korea's PCT filings increased markedly during the period, from 5.1 percent in 2006 to 9.4 percent in 2015, with the number of PCT filings rising from 306 in 2006 to 1,364 in 2015. In contrast, public research institute PCT filings decreased as a share of the total from 7.8 percent in 2006 to 3.6 percent in 2015, mainly because the overall number of PCT filings from the Republic of Korea increased faster than the number of public research institute filings.

Figure 3.9 shows data for a selection of middle-income countries. Indian public research institutes accounted for 9.6 percent of total Indian PCT filings in 2015, with 135 filings. The share for universities peaked at 6.5 percent in 2010, having increased regularly over the 
previous decade. It stood at 1.8 percent in 2006 and 3.4 percent in 2015, with fifteen and forty-eight PCT filings, respectively.

The share of university PCT filings from South Africa has increased markedly over the past decade, from 5.4 percent in 2006 to 18.1 percent in 2015. This reflects an increase in the number of PCT filings from twenty-three in 2006 to fifty-six in 2015. In contrast, the shares and numbers of PCT filings from South African public research institutes have remained stable since 2006; in 2015 South African public research

(a)
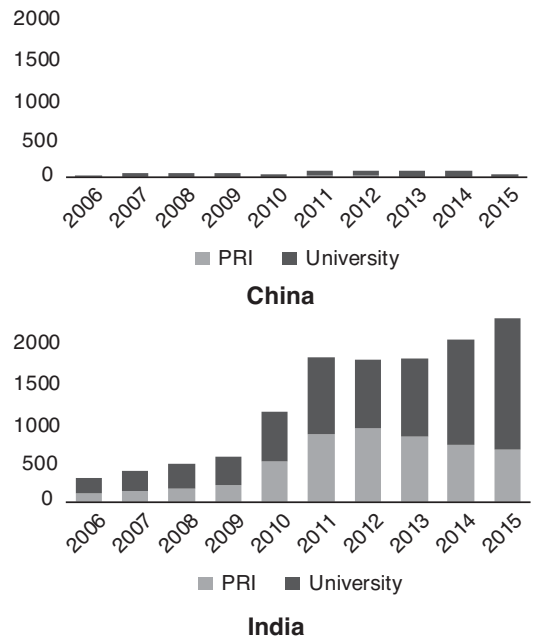

2000

1500

1000

500

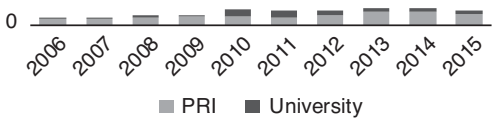

Malaysia

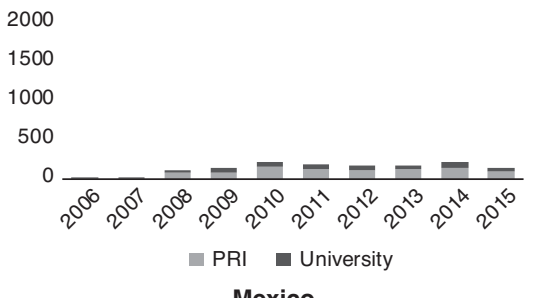

2000

1500

1000

500

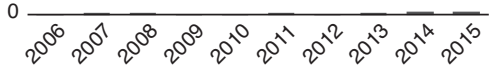

- PRI University

South Africa

2000

1500

1000

500

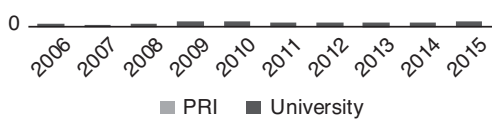

Figure 3.9 University and public research institute PCT filings in middle-income countries

3.9a Public research institute and university PCT applications from middle-income countries, absolute numbers, 2006-15

3.9b Share of public research institute and university PCT applications from middleincome countries, country shares (\%), 2006-15

Source: WIPO Statistics Database, April 2016 
(b)
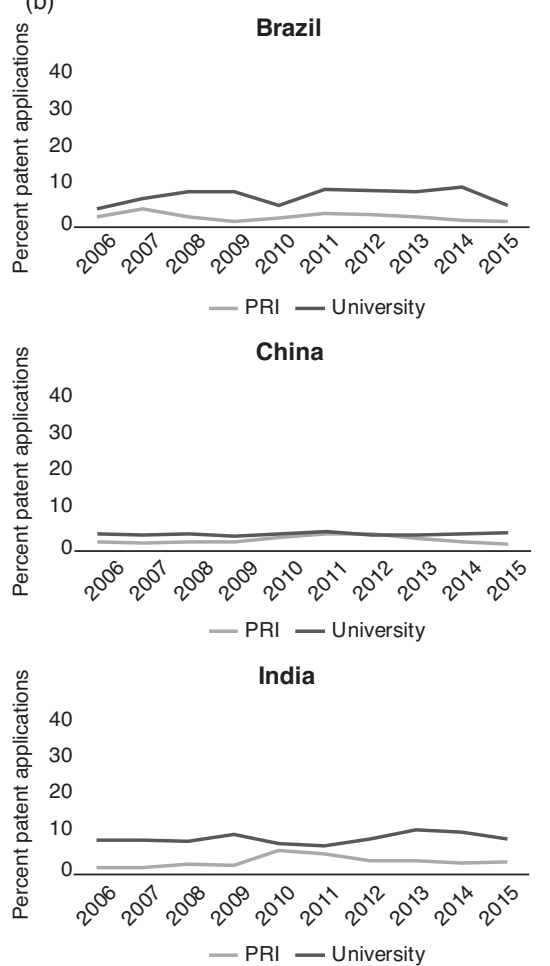

Figure 3.9 (cont.)
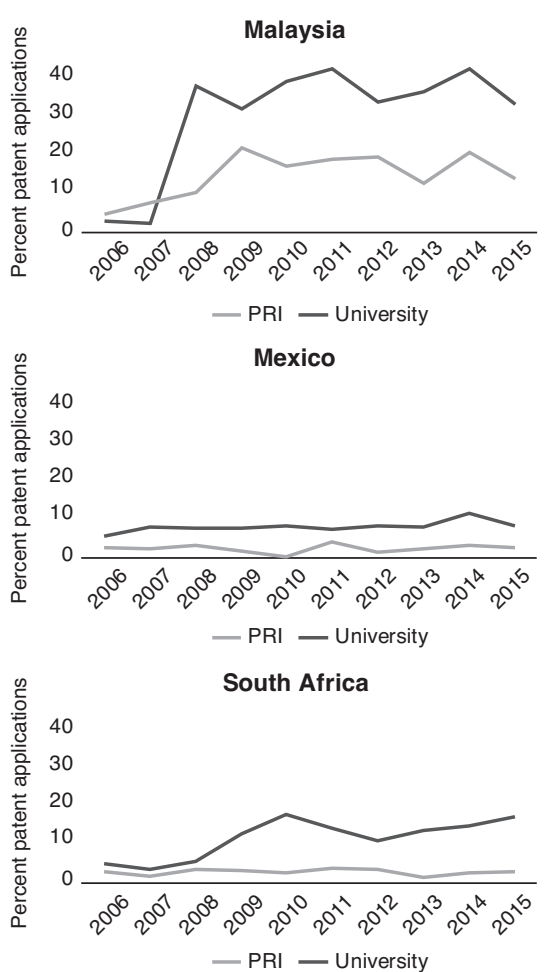

institutes filed ten PCT applications, representing 3.2 percent of the country's PCT filings.

As for Mexico, the numbers and shares of public research institute and university PCT filings remained small for the whole period. Mexican public research institutes and universities filed on average about twentyfive PCT applications per year each in most of the years reported, accounting for a maximum of 15.8 percent of total PCT filings from Mexico.

The share of public research institute PCT filings from Malaysia has increased sharply since 2006 and accounted for nearly half of total PCT filings originating from the country (44.0 percent). The number of public research institute filings increased from two in 2006 to ninety-two in 2015. Likewise, the share of university PCT filings increased, from 5.0 percent in 2006 to 14.5 percent in 2015, with numbers up from just three filings in 2006 to thirty-nine in 2015. University and public research 
institute PCT filings combined accounted for two-thirds (65.0 percent) of PCT filings from Malaysia in 2014.

Chinese university and public research institute PCT filings remained quite stable as a share of total Chinese PCT filings between 2006 and 2015 , with on average 4.7 percent and 3.1 percent respectively throughout this period. However, the numbers of PCT filings were six to eight times higher in 2015 than a decade earlier. The number of PCT filings for universities increased from 183 in 2006 to 1,547 in 2015, and from ninety-six to 607 for public research institutes.

(a)

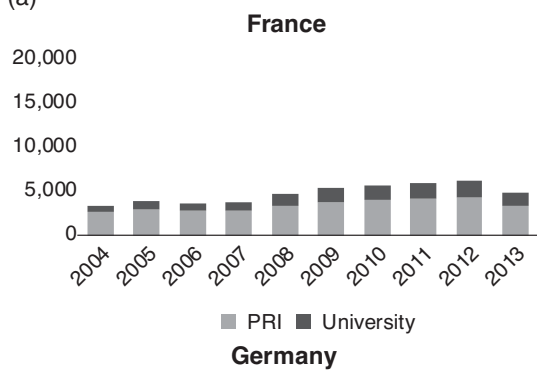

20,000

15,000

10,000

5,000

0

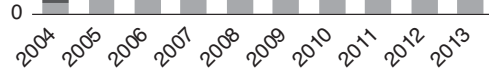

— PRI — University

Japan

20,000

15,000

10,000

5,000

0

$2^{0^{\alpha}} 2^{0^{0}} 2^{0^{0}} 2^{0^{1}} 2^{0^{8}} 2^{0^{9}} 2^{0^{0}} 2^{0^{1}} 2^{0^{12}} 2^{0^{3}}$

$\square$ PRI $\square$ University

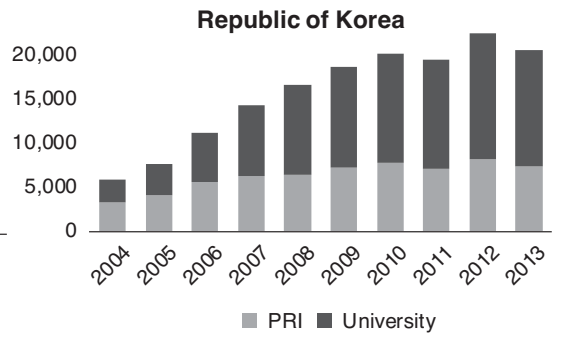

United Kingdom

20,000

15,000

10,000

5,000

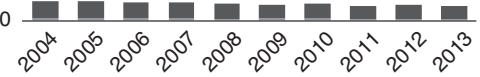

PRI U University

United States of America

20,000

15,000

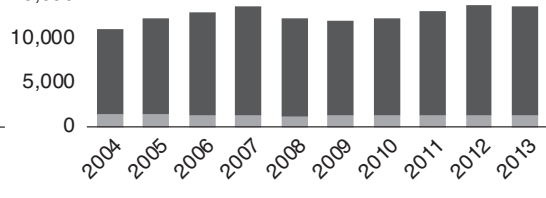

PRI $\square$ University

Figure 3.10 University and public research institute patent filings using PATSTAT data

3.10a Public research institute and university patent applications from high-income countries, absolute numbers, 2004-13

$3.10 \mathrm{~b}$ Public research institute and university patent applications from high-income countries, country shares (\%), 2004-13

Sources: WIPO Statistics Database and EPO PATSTAT database, April 2016 
(b)
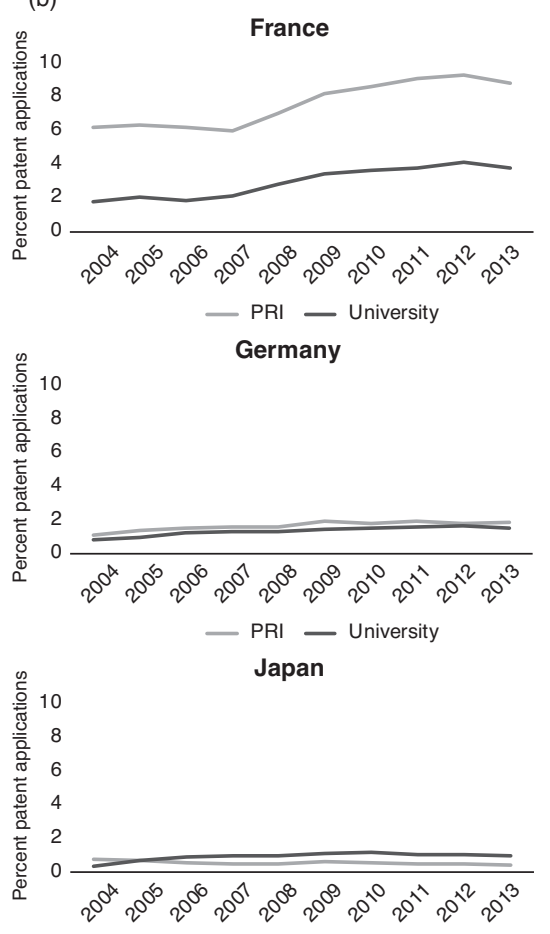

- PRI — University

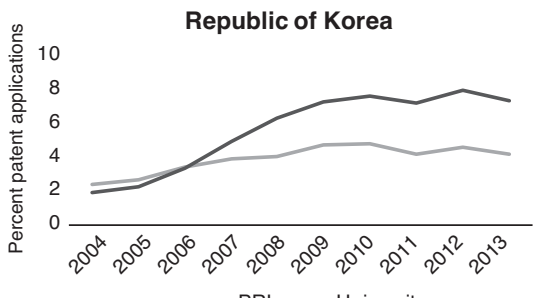

- PRI — University

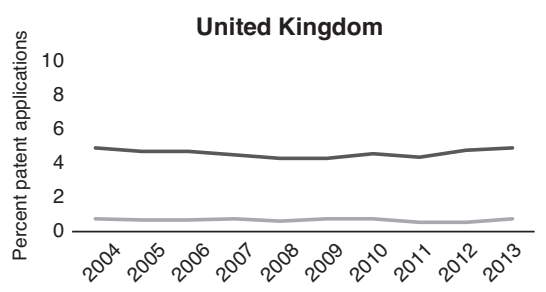

- PRI — University

United States of America

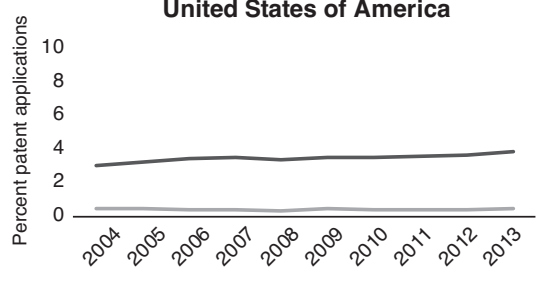

- PRI — University

Figure 3.10 (cont.)

According to PATSTAT data, university and public research institute patent filings in France increased by an average annual growth rate of 4.7 percent between 2004 and 2013, reaching 4,810 applications (Figures $3.10 \mathrm{a}$ and $3.10 \mathrm{~b}$ ). In Japan, the number of university and public research institute applications stood at 7,264 in 2010, but declined to 5,100 in 2013. In the Republic of Korea, 22,441 university and public research institute applications were filed in 2012, and the average annual growth rates is 15.9 percent in 2004-13.

Patents filed by US universities and public research institutes amounted to about 11,000 and 14,000 per year in the period 2004-13, with a decline to around 12,000 in 2005-10. US universities have been patenting their innovations for many years but because of the number of patents filed by the private sector, the university share stood at about 3.9 percent of total filings in 2013. 
In China, university and public research institute patent applications combined grew from 8,740 in 2004 to 111,397 in 2013, with an average annual growth rate of 33.2 percent since 2004 (Figures 3.11a and 3.11b). Chinese university patenting since 2004 shows a sharp increase in filing, making some Chinese universities among the most active in the world in terms of patent-filing activity. This can be explained in part by government grants to research institutes and universities that file a large number of patent applications, and related initiatives.

(a)
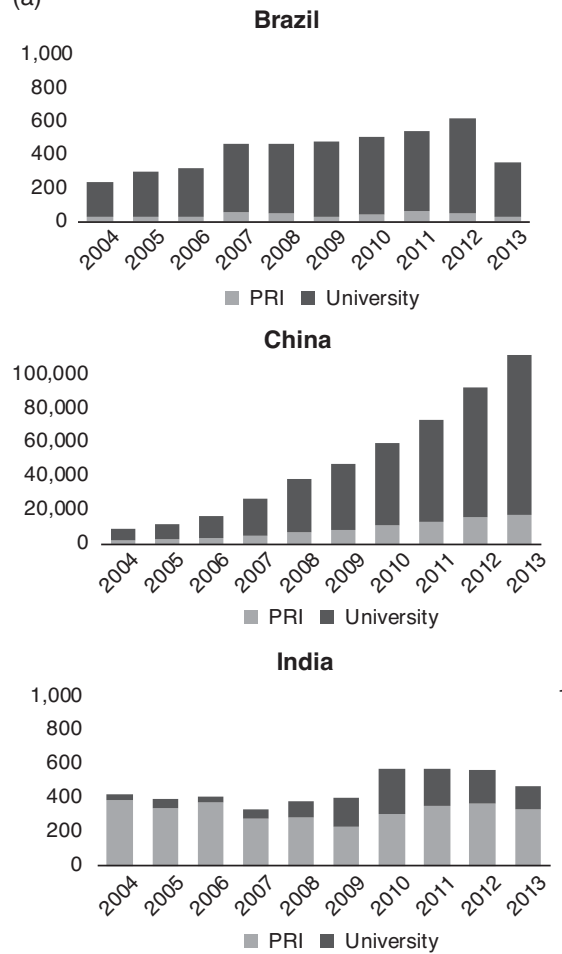

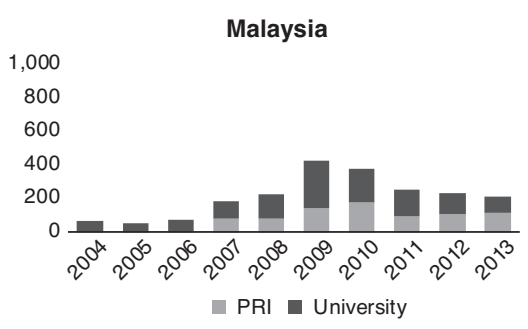

Mexico

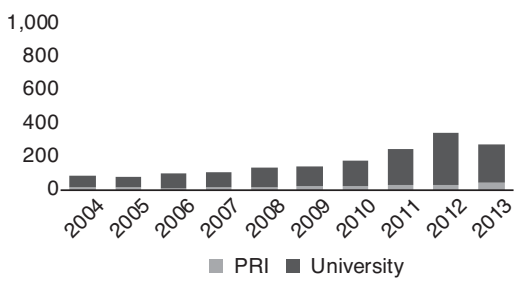

South Africa

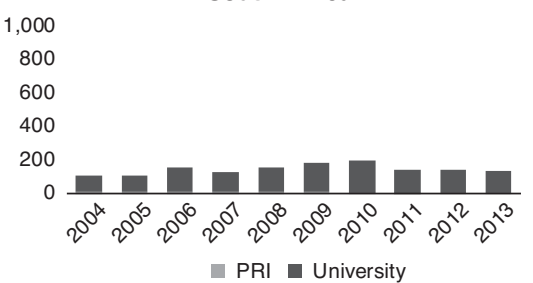

Figure 3.11 University and public research institute patent filings for middle-income countries

3.11a Public research institute and university patent applications from middle-income countries, absolute numbers, 2004-13

3.11b Public research institute and university patent applications from middle-income countries, country shares (\%), 2004-13

Sources: WIPO Statistics Database and EPO PATSTAT database, April 2016 

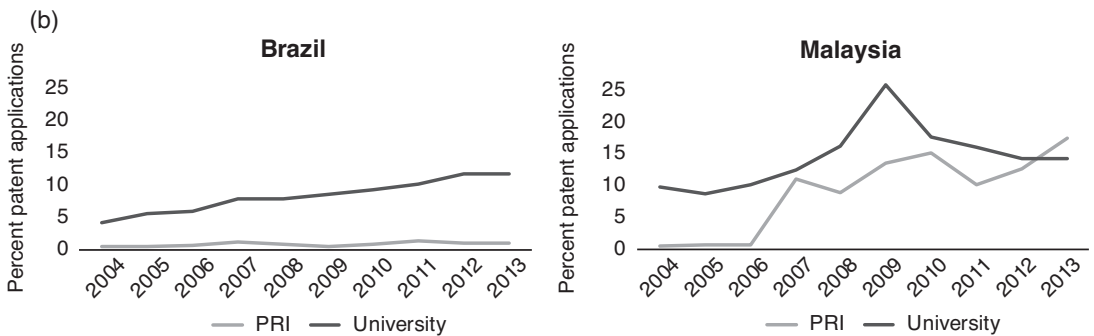

- PRI — University
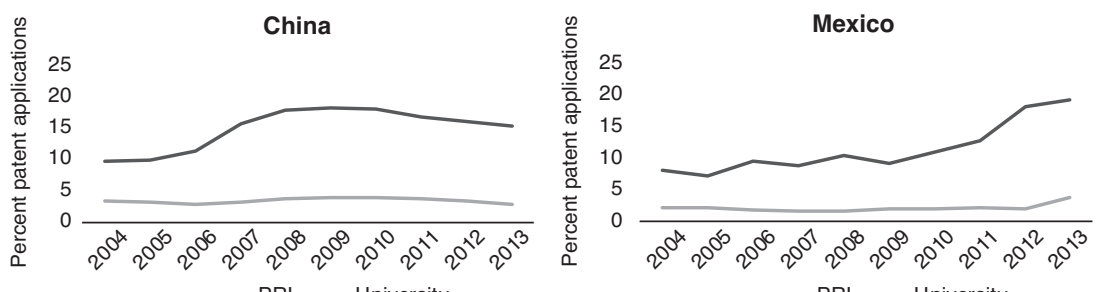

- PRI - University
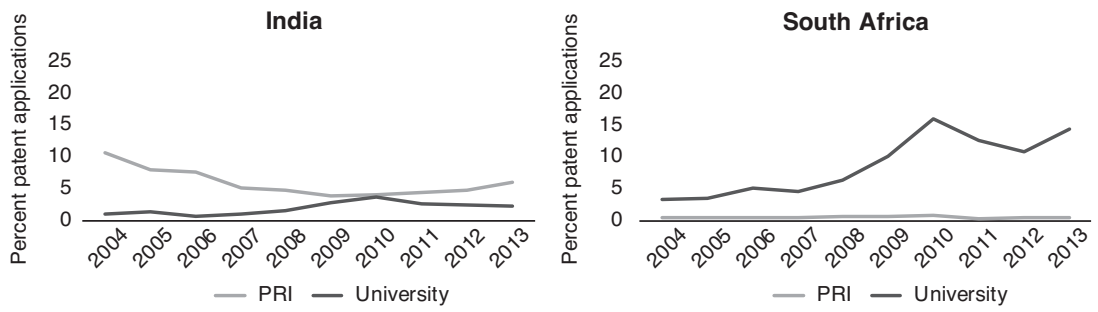

Figure 3.11 (cont.)

Two main points emerge from the above comparisons. First, the share of university and public research institute patent filings in all applications in high-income countries is more stable than their share in the middleincome group. Second, in terms of numbers of filings, middle-income countries are more heterogeneous than high-income countries.

Figure 3.12 shows the share of patent applications from universities and public research institutes in selected countries. The countries with the highest share of university filings in their total filings are China (14.8 percent), Malaysia (12.8 percent), Spain (6.9 percent), Israel (6.0 percent), Brazil (4.2 percent), and the Republic of Korea (4.2 percent). The countries with the highest share of public research institute applications are India (9.1 percent), France (5.7 percent), China (3.6 percent), the Republic of Korea (3.6 percent), and Spain (3.4 percent). 


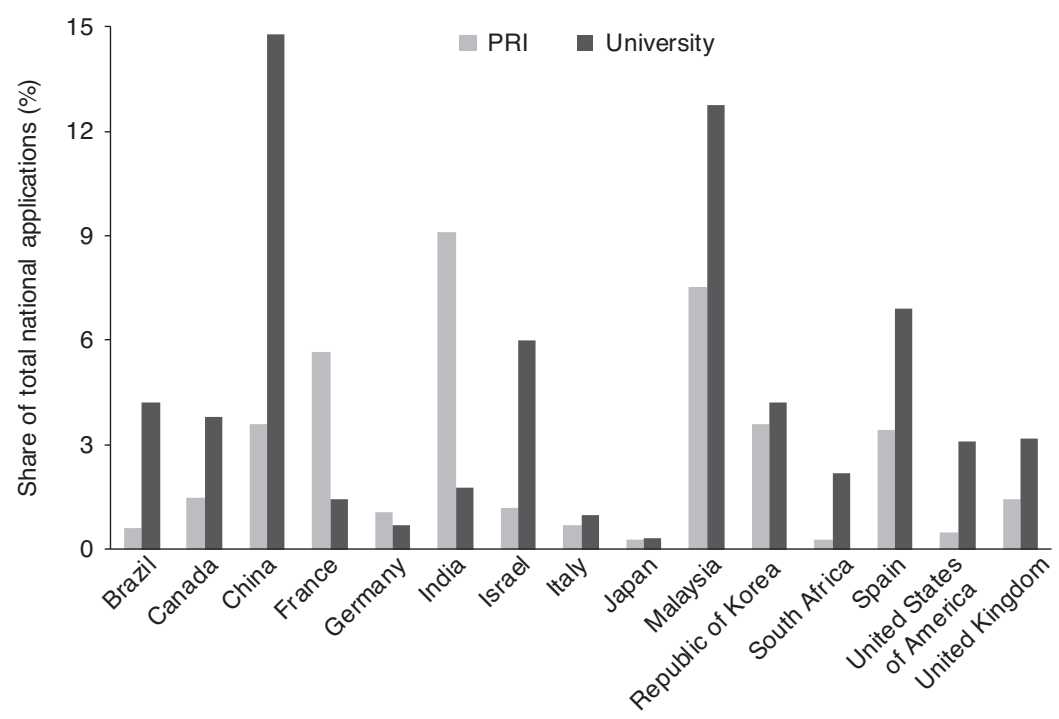

Figure 3.12 University and public research institute patent applications as a share of total applications for selected countries (\%), 1980-2013

Sources: WIPO Statistics Database and EPO PATSTAT database, April 2016

The shares of university and public research institute patent filings tend to be higher in the middle-income group than in the high-income group. It therefore seems particularly appropriate to encourage knowledge transfer in certain middle-income countries such as Brazil, China, India, Malaysia, and South Africa.

\subsubsection{By Technology Field}

Overall, university and public research institute patenting activity primarily concerns biomedical and pharmaceutical inventions, broadly defined. ${ }^{13}$ This is true of high-income countries and other economies alike. It is not surprising, as these industries are the most science-driven.

${ }^{13}$ WIPO's IPC technology concordance table was used in this section to convert IPC codes into corresponding fields of technology (see "Concept of a Technology Classification for Country Comparisons," Final Report to the World Intellectual Property Organization (WIPO), Ulrich Schmoch, June 2008). For an electronic version of the IPC technology concordance table, see www.wipo.int/ipstats. 

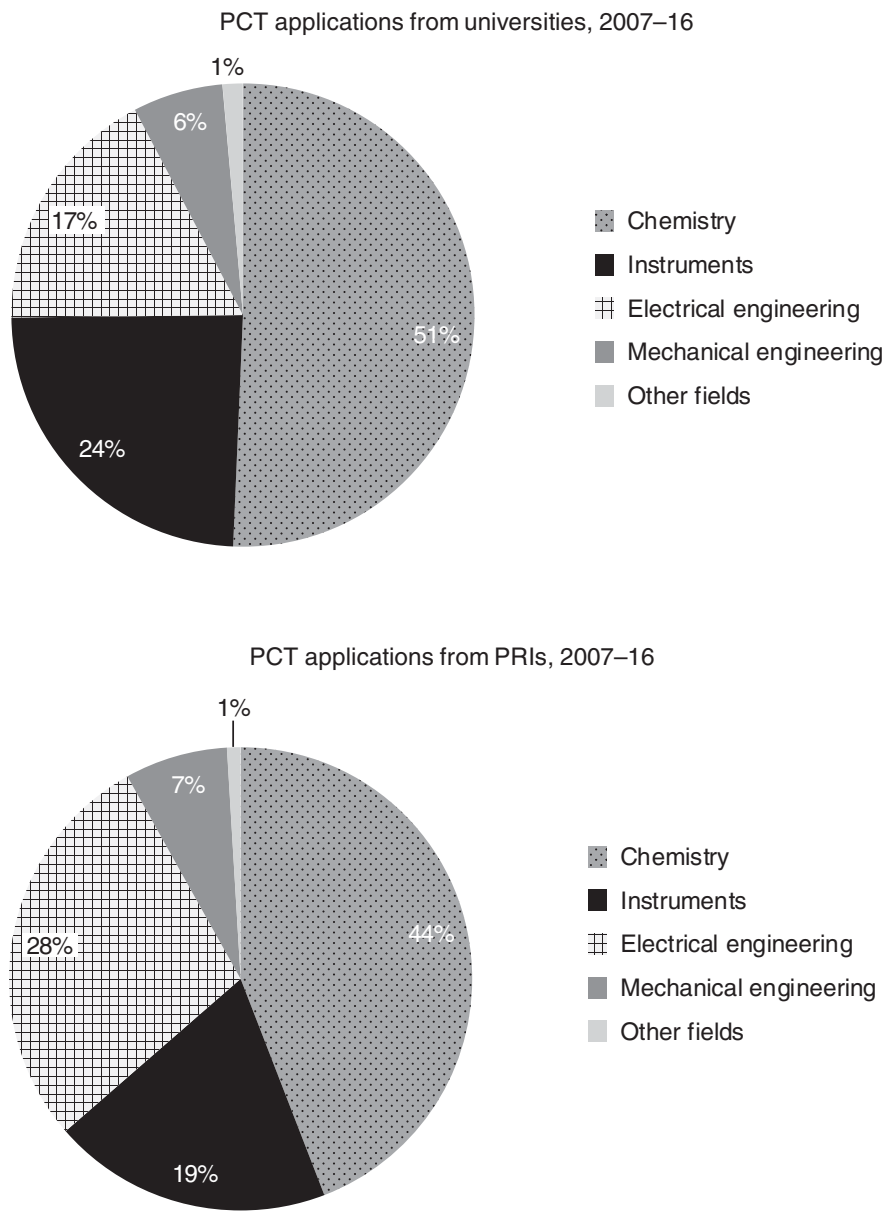

Figure 3.13 Distribution of PCT applications by technology sector, 2007-16 Source: WIPO Statistics Database, July 2016

However, whether patenting in these technological fields is demand- or supply-driven is less clear.

On the basis of PCT data, it can be shown that for the period 2007-16, university filings mainly occurred in the chemistry sector (51 percent) (Figure 3.13), followed by instruments (24 percent), and electrical engineering (17 percent). The three sectors combined accounted for 92 percent of PCT applications filed by universities. 
Public research institutes also made their largest share of PCT applications in the chemistry sector (44 percent). Their share of PCT applications filed in the electrical engineering sector was relatively high, at 28 percent of their total filings. Together with instruments (20 percent), the top three sectors for public research institutes accounted for 92 percent of their total filings, precisely like the cumulative share of the top three sectors for universities.

In 2016, universities filed the largest number of PCT applications in the fields of pharmaceuticals (15 percent), biotechnology (13 percent), and medical technology (10 percent) (see Figure 3.14). These were also the top three fields for public research institutes. For public research institutes, pharmaceuticals accounted for 12 percent of total PCT filings, as did biotechnology. Medical technology represented 8 percent of public research institutes' total PCT filings.

Table 3.2 shows the share of patent applications filed worldwide by universities and public research institutes for selected technology fields in 2013-15, based on data from the PATSTAT database. Of the thirty-five technology fields, university applicants filed 40 percent of their applications in their top five fields: biotechnology (14.9 percent), pharmaceuticals ( 8.5 percent), measurement (5.7 percent), materials, metallurgy (5.5 percent), and organic fine chemistry (5.3 percent).

- University $\quad$ PRI

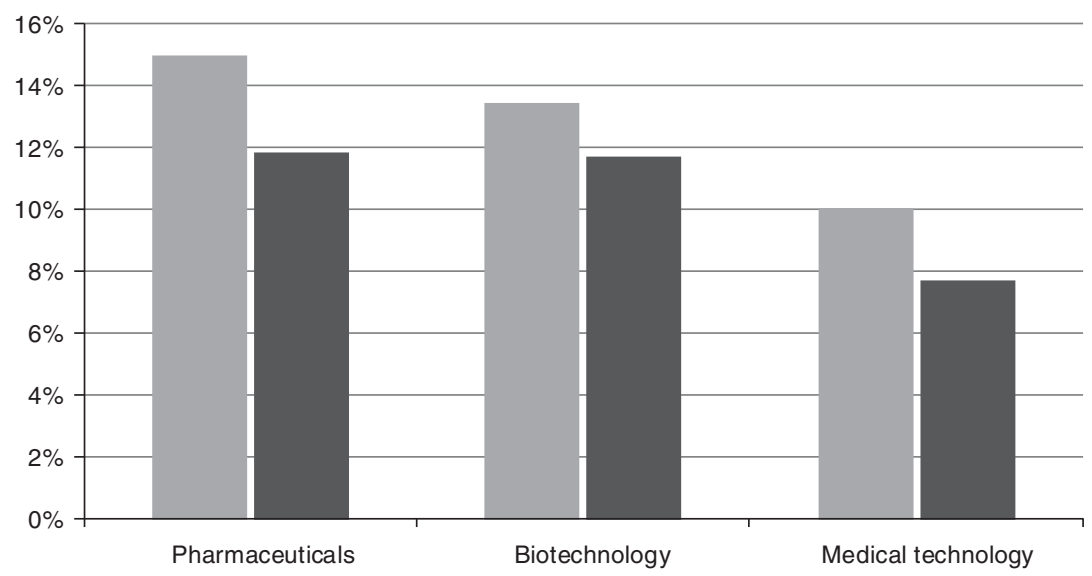

Figure 3.14 Share of PCT applications for the top three fields of technology, 2016 Source: WIPO Statistics Database, July 2016 
Table 3.2 Share of patent applications filed in selected technology fields by applicant type, 2013-15

\begin{tabular}{|c|c|c|c|}
\hline Technology field & Applicant type & Patent filings & $\begin{array}{l}\text { As a share of all } \\
\text { university/public } \\
\text { research institute } \\
\text { filings }(\%)\end{array}$ \\
\hline Biotechnology & University & 184,175 & 14.9 \\
\hline Pharmaceuticals & University & 183,509 & 8.5 \\
\hline Measurement & University & 143,493 & 5.7 \\
\hline Materials, metallurgy & University & 80,614 & 5.4 \\
\hline $\begin{array}{l}\text { Organic fine } \\
\text { chemistry }\end{array}$ & University & 114,147 & 5.3 \\
\hline Chemical engineering & University & 72,235 & 4.3 \\
\hline $\begin{array}{l}\text { Basic materials } \\
\text { chemistry }\end{array}$ & University & 66,177 & 3.6 \\
\hline $\begin{array}{l}\text { Other special } \\
\text { machines }\end{array}$ & University & 58,141 & 2.8 \\
\hline Computer technology & University & 91,807 & 2.7 \\
\hline $\begin{array}{l}\text { Electrical machinery, } \\
\text { apparatus, energy }\end{array}$ & University & 77,325 & 2.3 \\
\hline Biotechnology & $\begin{array}{l}\text { Public research } \\
\text { institute }\end{array}$ & 64,110 & 5.2 \\
\hline Measurement & $\begin{array}{l}\text { Public research } \\
\text { institute }\end{array}$ & 62,151 & 2.5 \\
\hline Pharmaceuticals & $\begin{array}{l}\text { Public research } \\
\text { institute }\end{array}$ & 48,923 & 2.3 \\
\hline Materials, metallurgy & $\begin{array}{l}\text { Public research } \\
\text { institute }\end{array}$ & 31,605 & 2.1 \\
\hline Chemical engineering & $\begin{array}{l}\text { Public research } \\
\text { institute }\end{array}$ & 33,323 & 2.0 \\
\hline $\begin{array}{l}\text { Organic fine } \\
\text { chemistry }\end{array}$ & $\begin{array}{l}\text { Public research } \\
\text { institute }\end{array}$ & 42,277 & 2.0 \\
\hline $\begin{array}{l}\text { Basic materials } \\
\text { chemistry }\end{array}$ & $\begin{array}{l}\text { Public research } \\
\text { institute }\end{array}$ & 31,323 & 1.7 \\
\hline $\begin{array}{l}\text { Other special } \\
\text { machines }\end{array}$ & $\begin{array}{l}\text { Public research } \\
\text { institute }\end{array}$ & 28,653 & 1.4 \\
\hline Computer technology & $\begin{array}{l}\text { Public research } \\
\text { institute }\end{array}$ & 37,728 & 1.1 \\
\hline $\begin{array}{c}\text { Electrical machinery, } \\
\text { apparatus, energy }\end{array}$ & $\begin{array}{l}\text { Public research } \\
\text { institute }\end{array}$ & 33,861 & 1.0 \\
\hline
\end{tabular}

Sources: WIPO Statistics Database and EPO PATSTAT database, April 2016 
Patent applications filed by public research institutes were not as concentrated among their top five (14.1 percent) as universities. These top five fields were: biotechnology (5.2 percent), measurement (2.5 percent), pharmaceuticals (2.3 percent), materials, metallurgy ( 2.1 percent), and chemical engineering ( 2 percent).

As described already, universities and public research institutes largely concentrate their filings - patent filings as well as PCT filings - in sciencebased technology fields, especially in pharmaceuticals and the biological fields.

The five universities that filed the largest number of PCT applications in 2016 were all in the U.S. (Figure 3.15). They mainly filed in pharmaceuticals and biotechnology. Pharmaceuticals accounted for the largest share of PCT filings by Johns Hopkins University and the University of Texas System, while biotechnology was the main field of technology for Harvard University, MIT, and the University of California.

The top five public research institutes in PCT filings were more diversified. Only ASTAR and INSERM had two of their three main technology fields belonging to the chemistry sector. China Academy of Telecommunication Technology filed the bulk of its applications in digital communications. The Commissariat à l'Energie Atomique et aux Energies Alternatives (CEA) and the Fraunhofer-Gesellschaft had each of their three main fields of technology within the electrical engineering sector.

Figure 3.16 shows the share of the top three fields of technology for selected universities and public research institutes in their total patent families created worldwide in 2010-13. All selected universities and public research institutes created a quarter or more of their patent families in their top three fields of technology. Precisely half the patent families created by the Korea Electronics Telecomm belonged to digital communications, telecommunications, and computer technology. The CEA is also highly concentrated in its top three fields of technology (electrical machinery, measurements, and semiconductors) as these three fields accounted for 41.3 percent of its total families.

Among this selection of ten universities and public research institutes, eight had measurement and six electrical machinery among their top three fields of technology. Pharmaceuticals and biotechnology - which are two popular fields of technology among universities and public research institutes - appears only among the top three fields of one public research institute (CNRS) and one university (Tokyo 

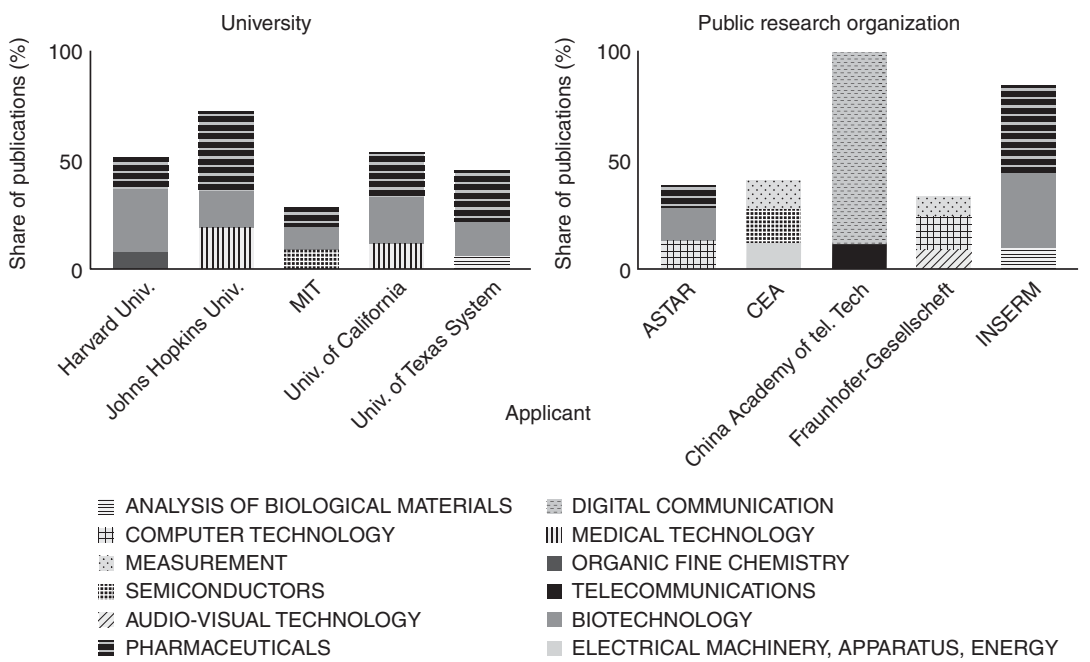

Figure 3.15 Shares of leading technology sectors in PCT applications filed by the top five universities

Source: WIPO Statistics Database, April 2017

Note: ASTAR is the Agency of Science, Technology and Research, CEA is the Commissariat à I'Énergie Atomique et aux Énergies Alternatives, INSERM is the Institut National de la Santé et de la Recherche Médicale, MIT is the Massachusetts Institute of Technology. Public research organizations include private organizations and hospitals. For confidentially reasons, data are based on publication date. WIPO's IPC technology concordance (available at: www.wipo.int/ipstats) was used to convert IPC symbols into thirty-five corresponding fields of technology.

University). This is due to the selection of universities and public research institutes, which shows that large organizations can be specialized in quite different fields of technologies.

\subsubsection{By University}

The University of California was the largest user of the PCT System in 2016, with 434 published PCT applications (Table 3.3). It has maintained that position since 1993. Massachusetts Institute of Technology (236) ranked second, followed by Harvard University (162), Johns Hopkins University (158), and the University of Texas System (152). Seven of the top ten universities were located in the U.S.; Seoul National University of the Republic of Korea (122) - in sixth position - was the highest-ranking non-US university, while Japan's University of Tokyo (108) ranked 


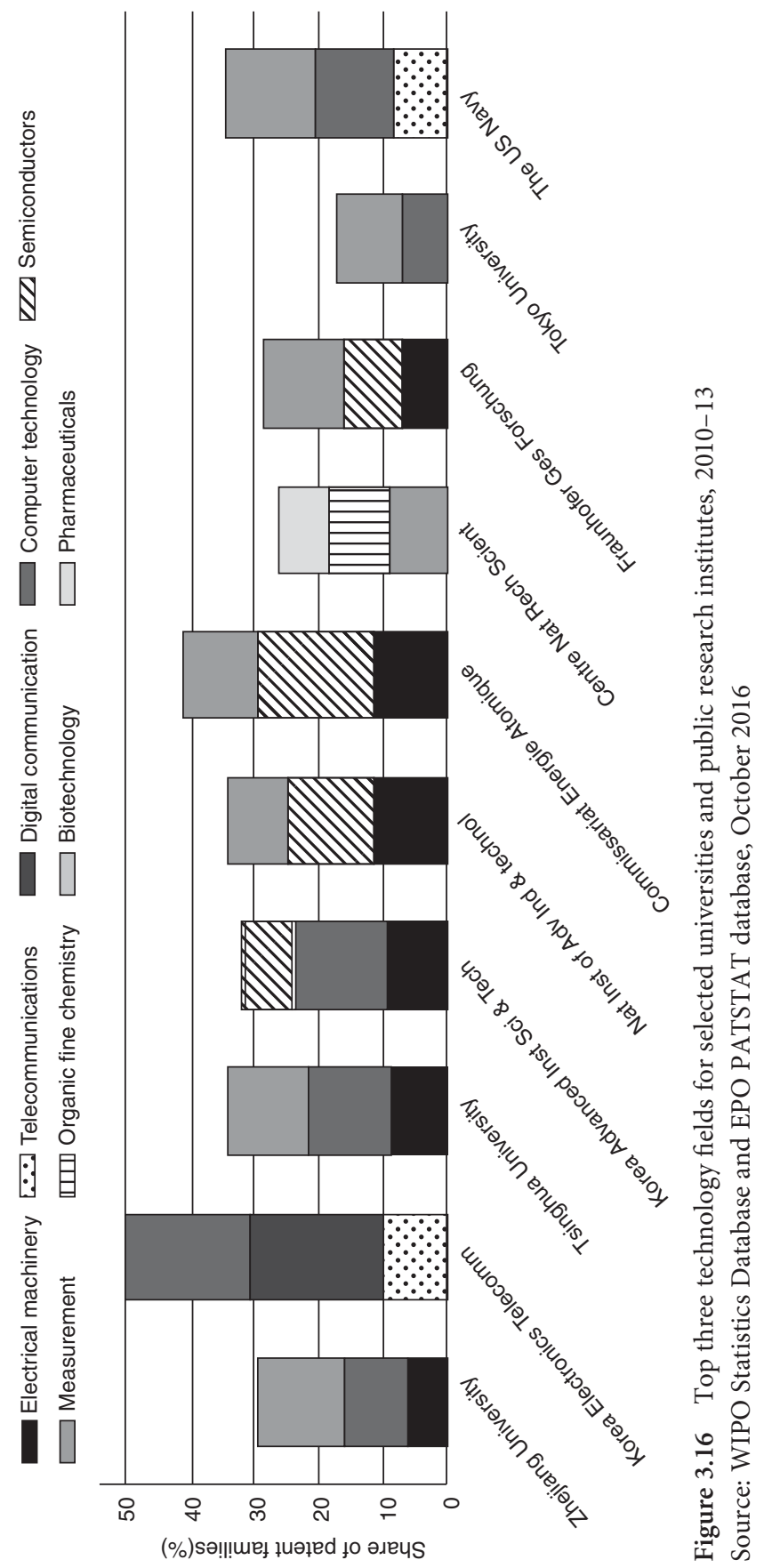


seventh. While the top ten was dominated by U.S.-based organizations, the top twenty list comprised ten US and ten Asian universities. China's Shenzhen University was in joint thirteenth position with eighty-seven published PCT applications, making it the highest-ranking Chinese university for PCT filings.

For the sixth consecutive year, the CEA of France was the top PCT applicant among public research institutes, with 329 published PCT applications (Table 3.4). It was followed by the FraunhoferGesellschaft zur Förderung der angewandten Forschung of Germany (252) and the Agency of Science, Technology and Research of Singapore (162).

Figure 3.17 shows the distribution of PCT applications for the top thirty origins, broken down by four types of applicant: businesses, individuals, universities, and government and research organizations. In 2016, 85.5 percent of all PCT applications belonged to business applicants, 7.5 percent to individuals, 5 percent to universities and 2 percent to public research institutes. Among the top thirty origins, universities accounted for a large share of applications in Morocco (42.9 percent), Colombia (33.7 percent), South Africa (16.2 percent), and Malaysia (14.4 percent). These five origins all belong to the middle-income category. They were followed by applicants from Singapore (14 percent), Spain (13.6 percent), Israel ( 9 percent), Australia ( 8.9 percent), and the United Kingdom (8.6 percent). In contrast, several countries - including Egypt, the Philippines and Sweden - had no PCT applications filed by universities in 2016.

Public research institutes represented a high share of applications originating in Malaysia (22.5 percent), Singapore (17.8 percent), the Philippines (11.8 percent), India (9.5 percent), and France ( 9.3 percent). Eleven of the top thirty origins had no PCT filing activity from public research institutes in 2016. For Colombia (33.7 percent), Malaysia (36.9 percent), and Morocco (42.9 percent), university and public research institute PCT filings combined accounted for more than onethird of their total PCT filings.

With 34,352 patent families worldwide, Panasonic of Japan was the top PCT applicant for the period 2010-13 (Table 3.5). It was followed by two other Japanese companies: Canon $(29,036)$ and Toyota Jidosha $(26,844)$. The top 100 list mainly comprises multinational companies. However, eleven Chinese universities and one Korean university as well as one Korean public research institute feature among the top 100 applicants. 


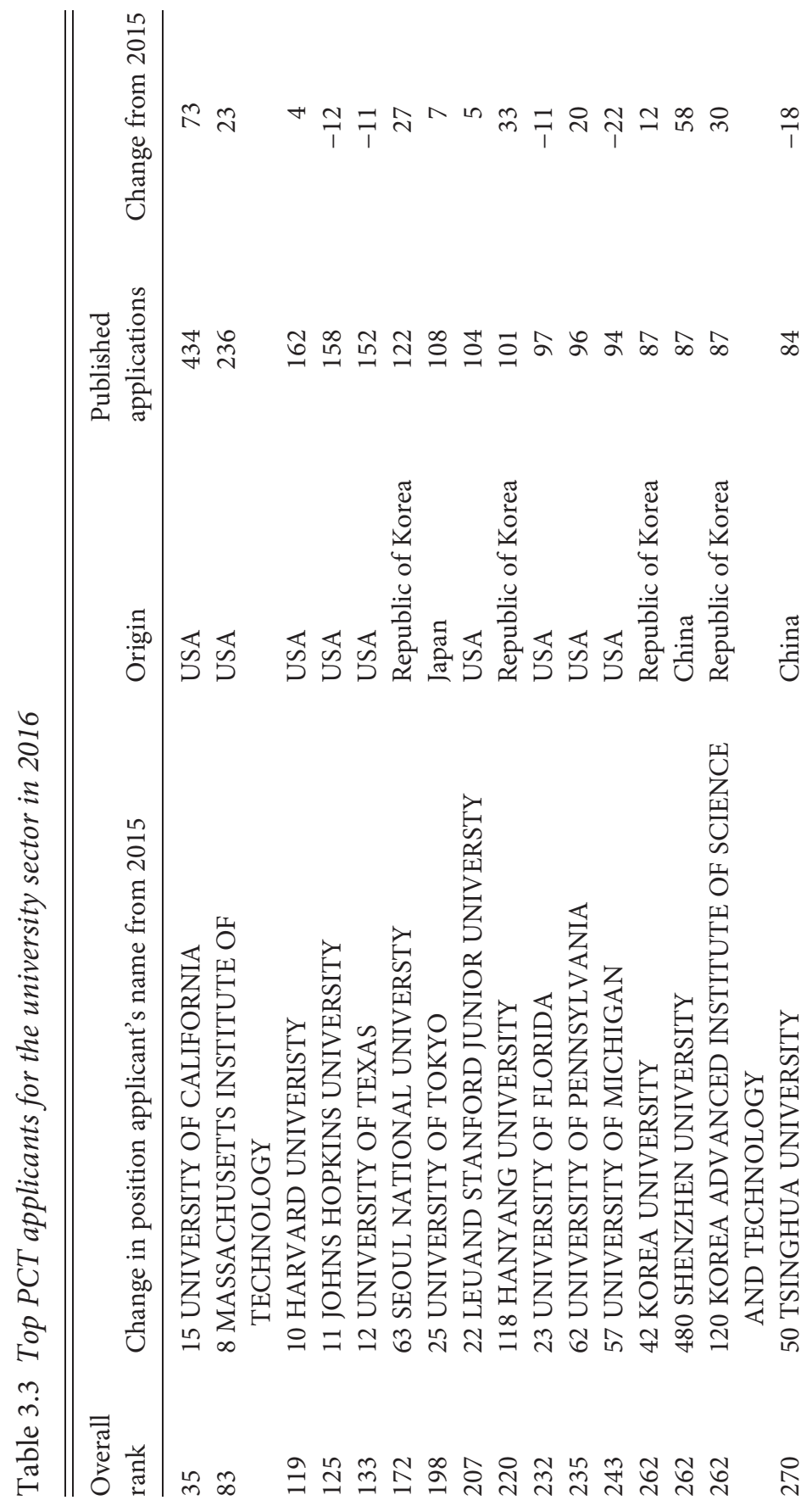




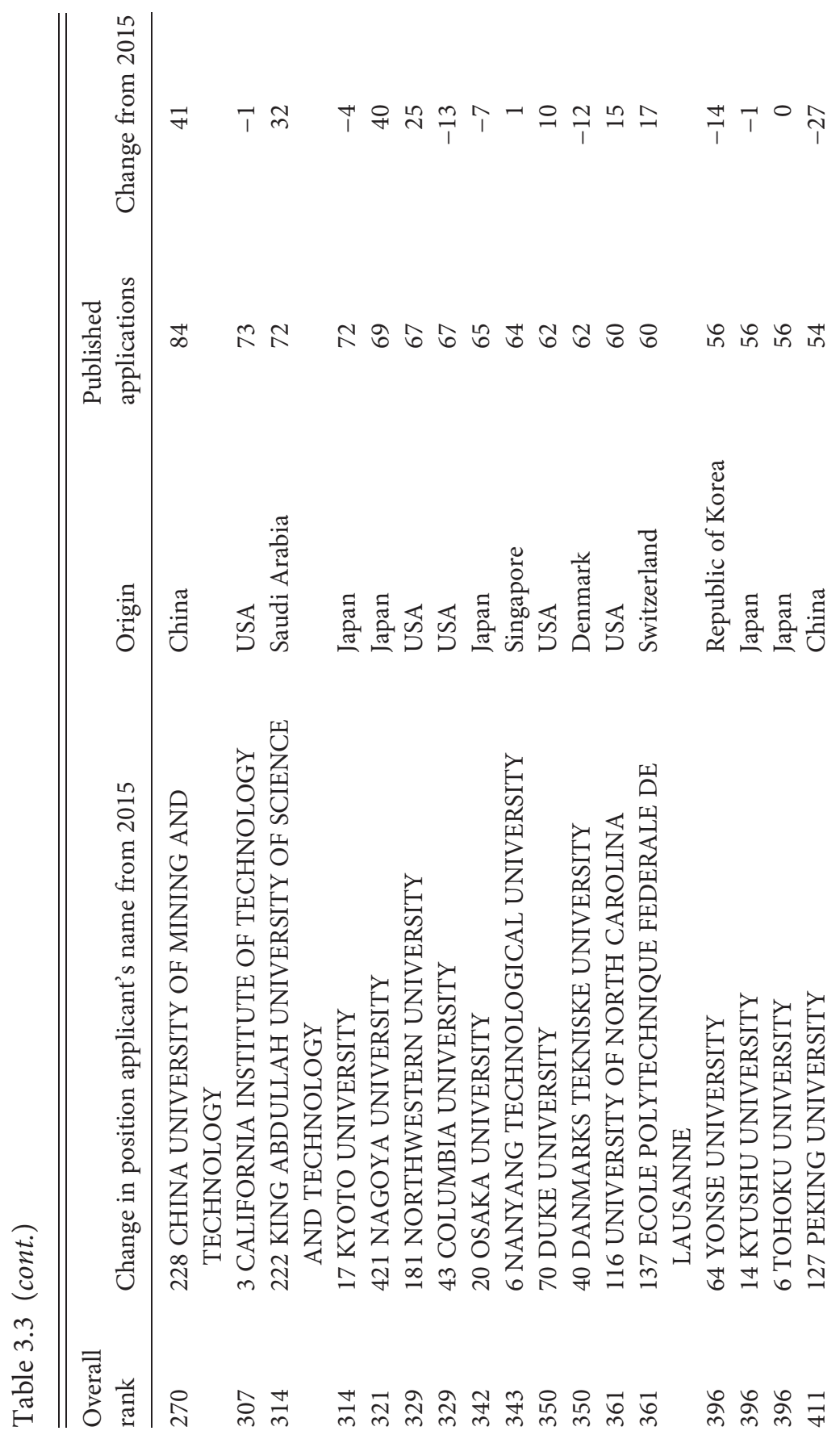




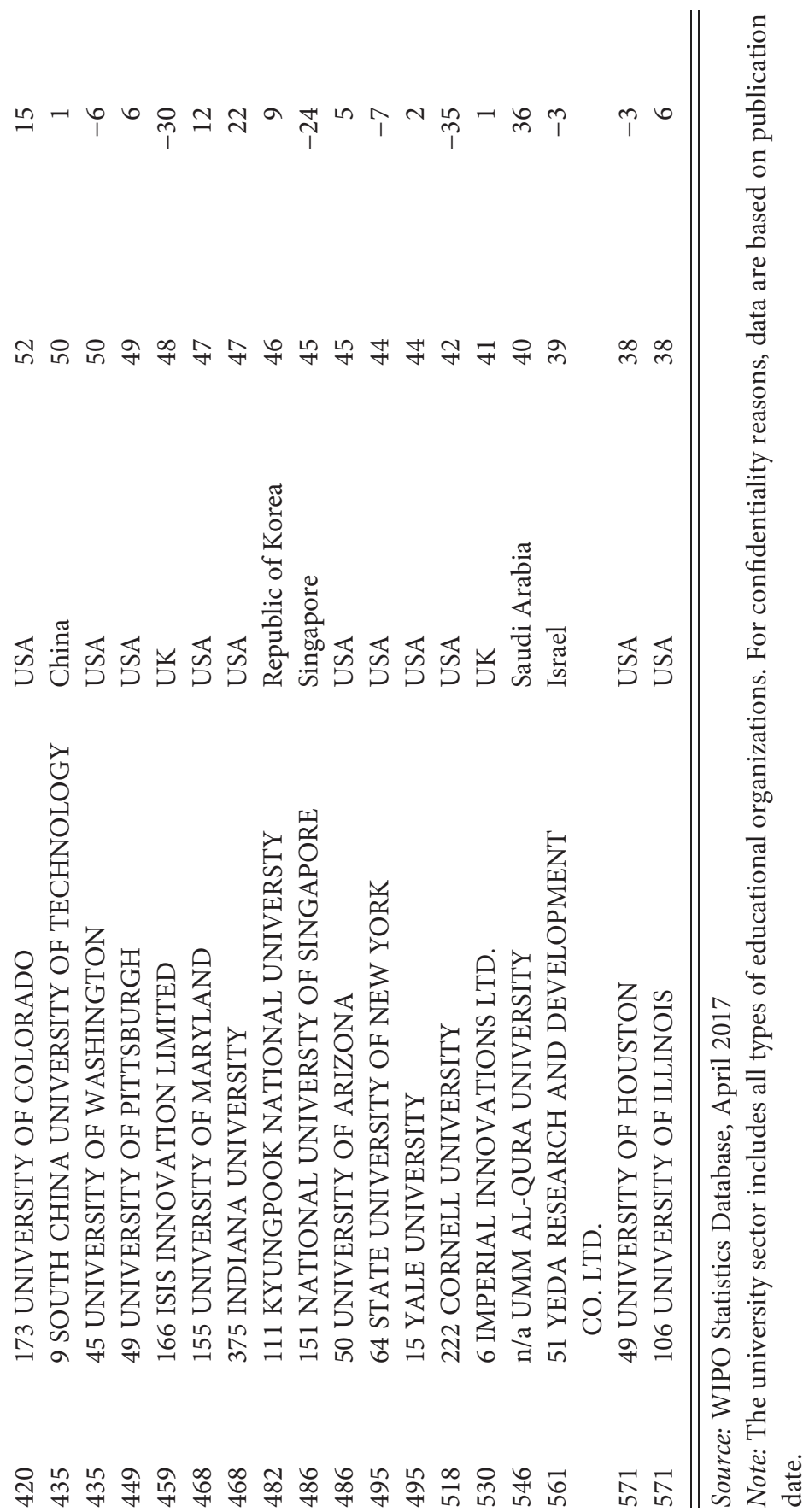




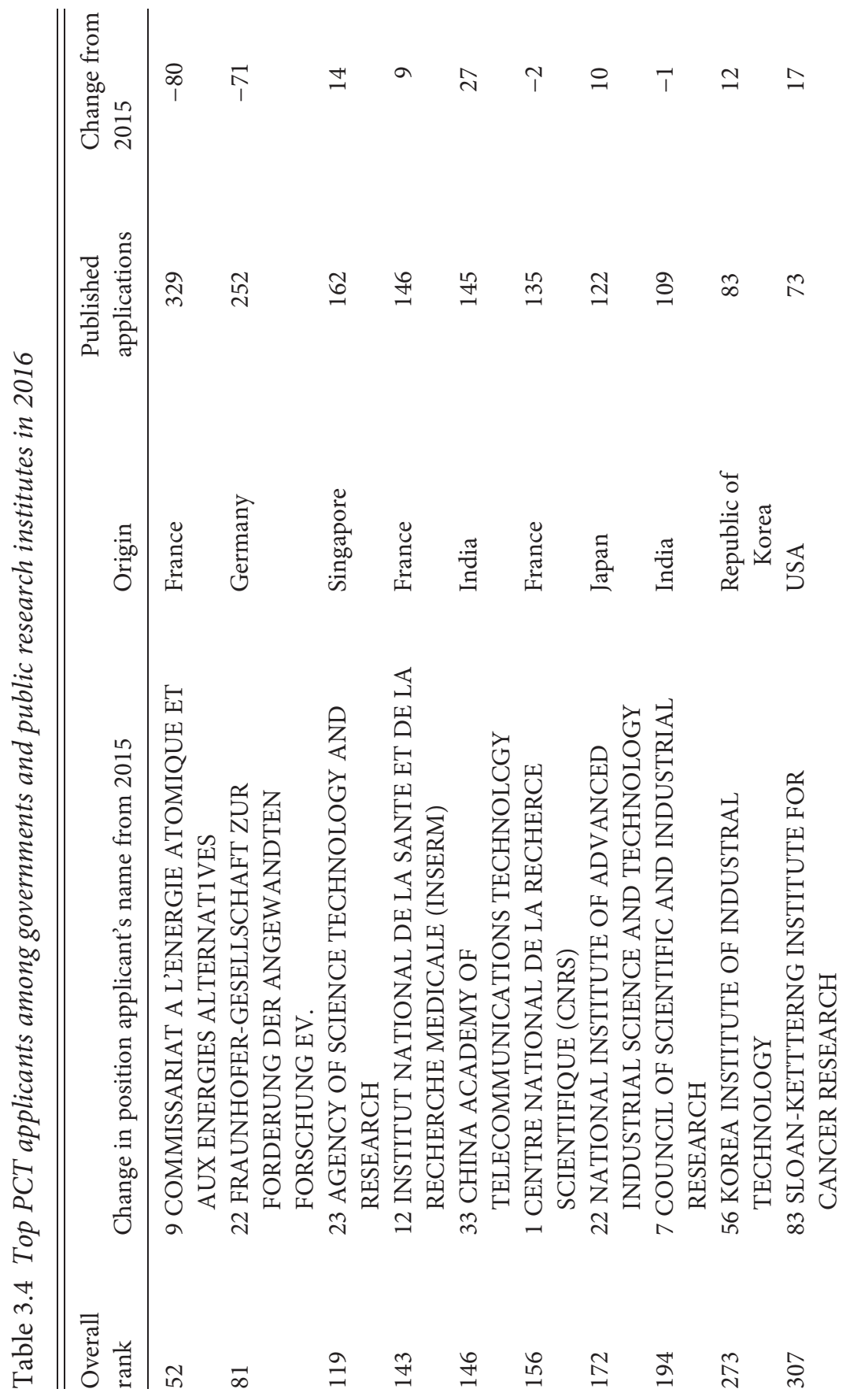




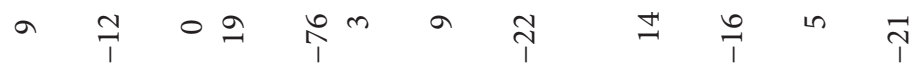

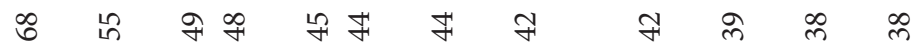

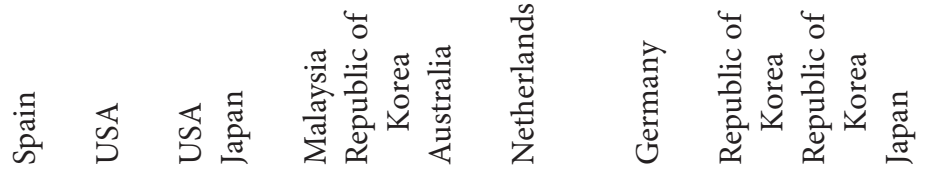

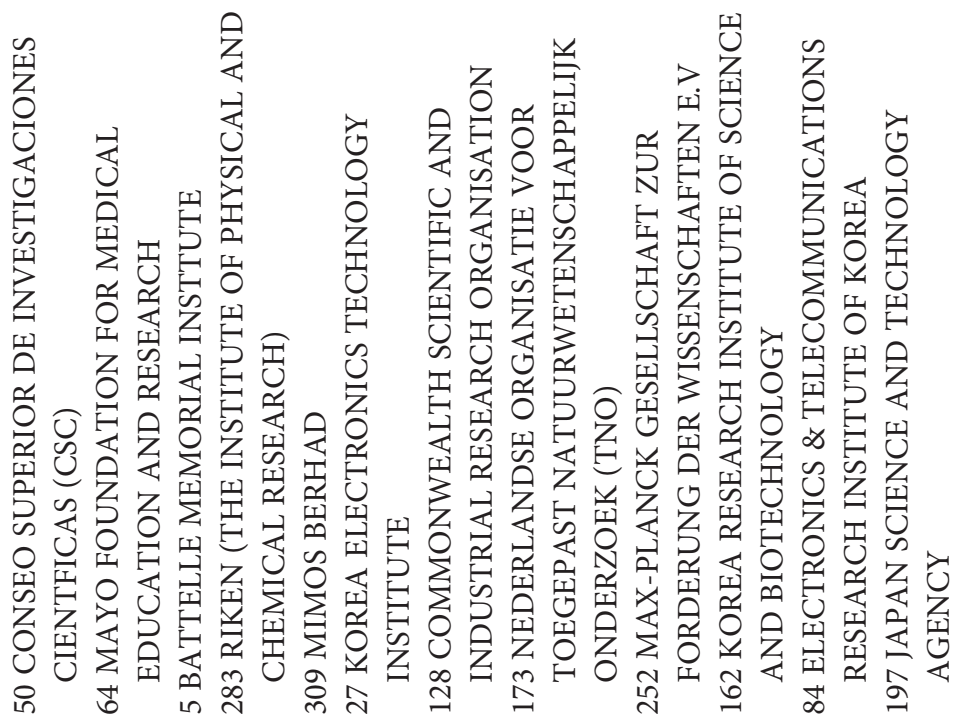

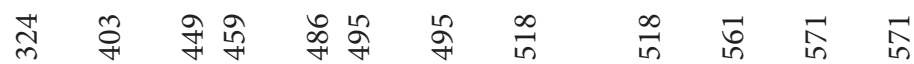




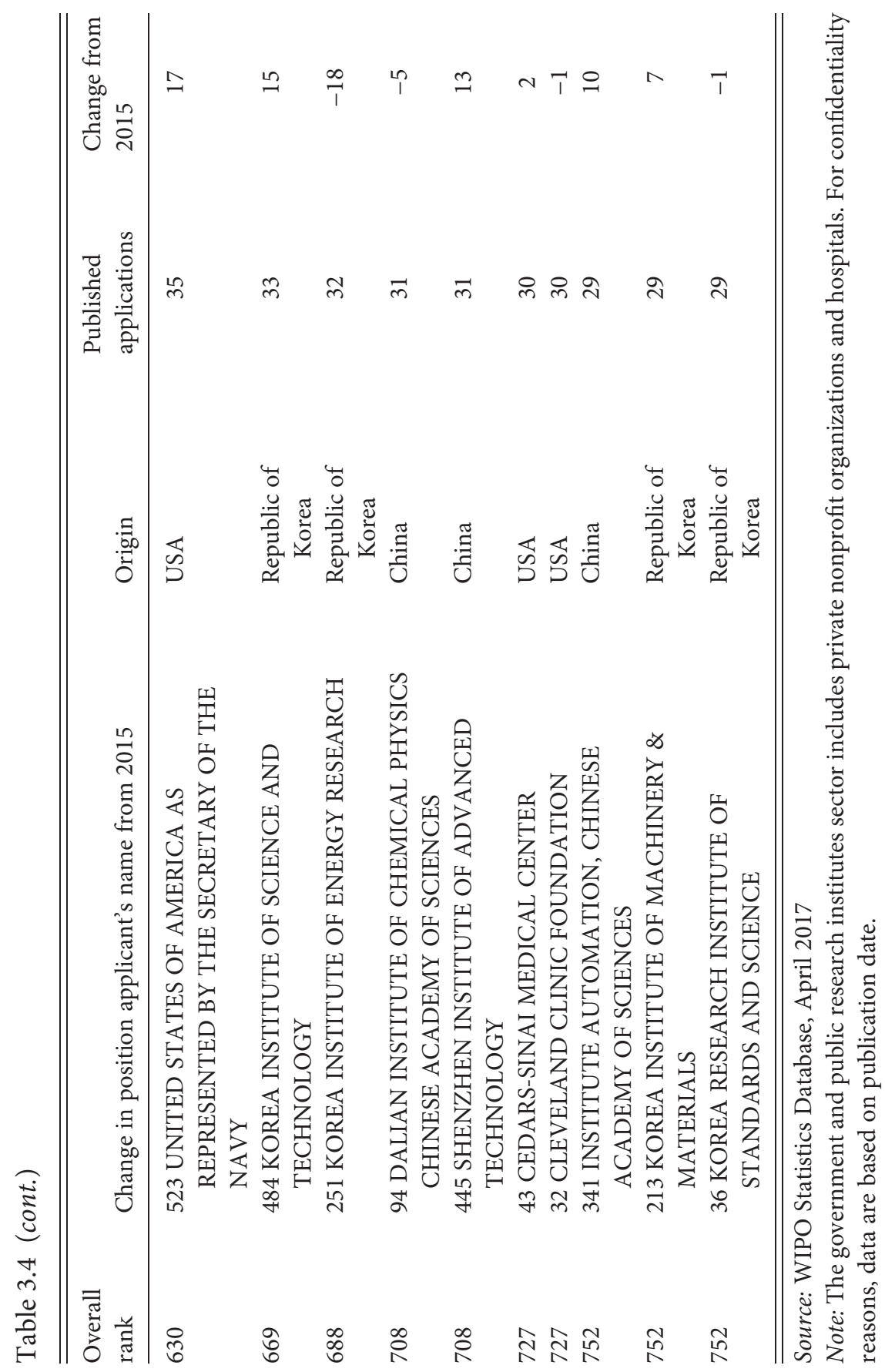




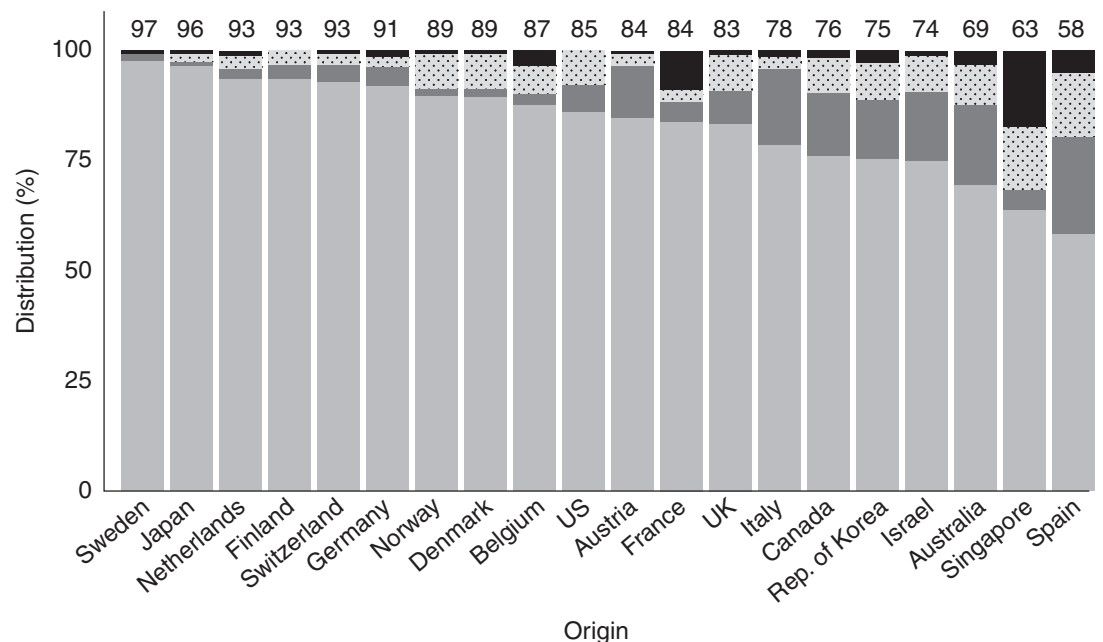

BUSINESS —INDIVIDUAL U UNIVERSITY — GOVERNMENT/PRI

Middle-income group

BUSINESS SECTOR SHARE (\%)

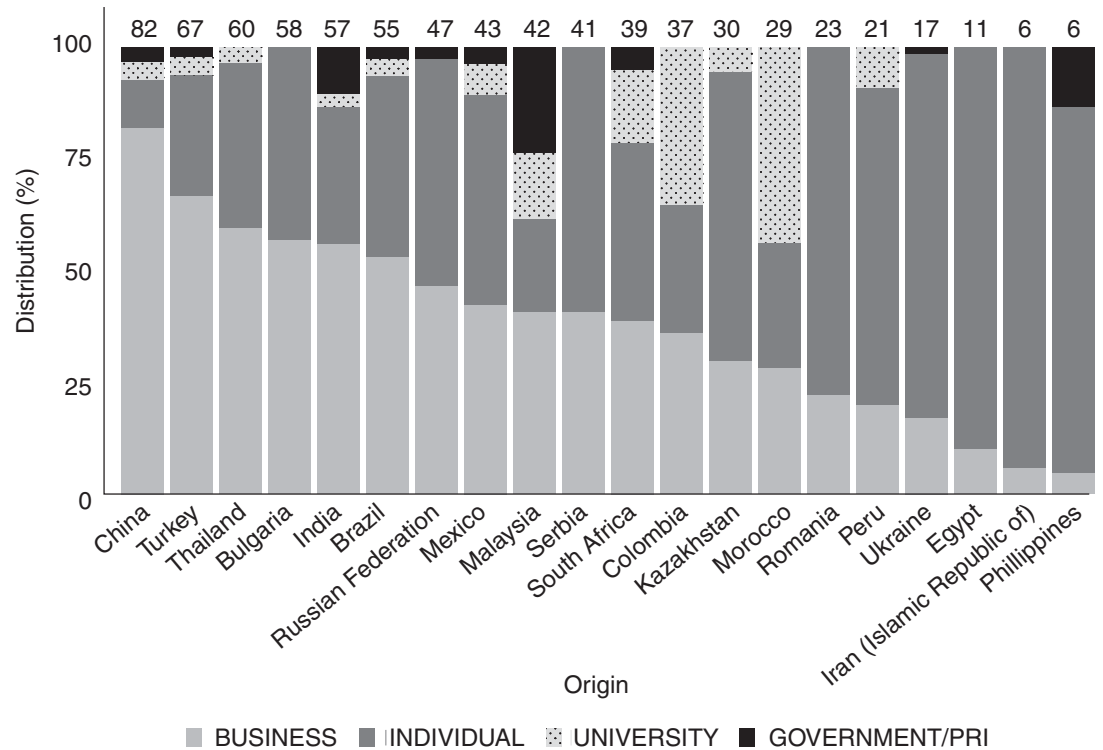

Figure 3.17 The share of the business sector in total PCT applications from selected origins

Source: WIPO Statistics Database, April 2017

Note: The government and public research organizations (PROs) sector includes private nonprofit organizations and hospitals. The university sector includes all educational institutions. For confidentiality reasons, data are based on the publication date. 


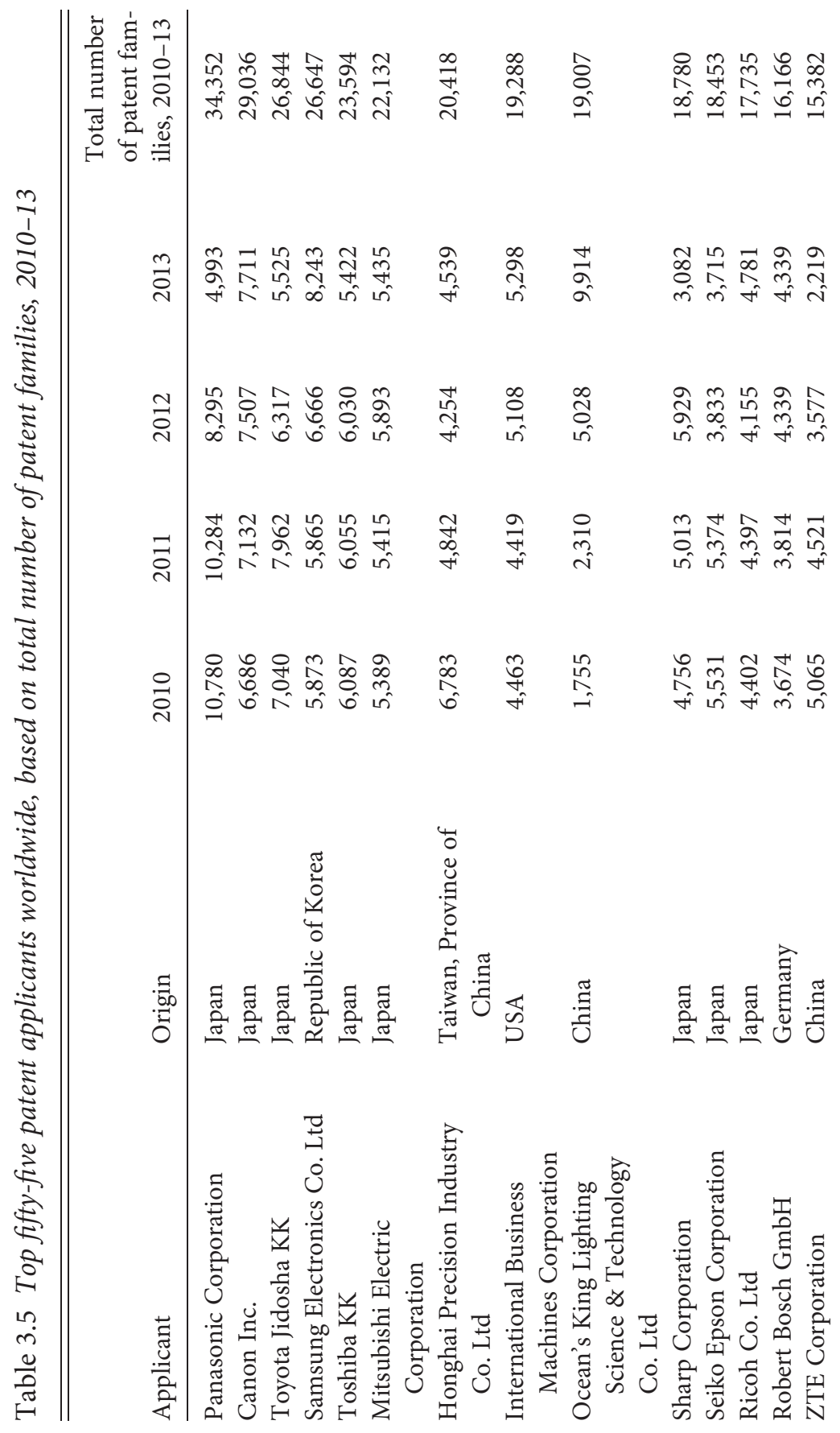




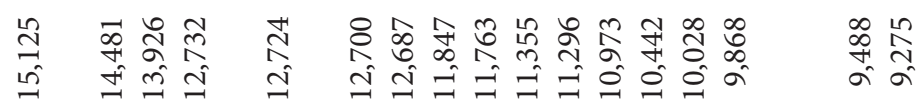

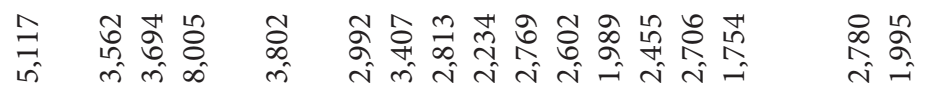

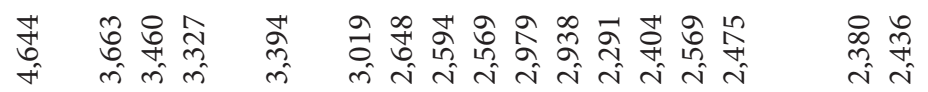

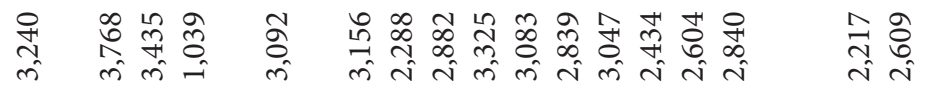

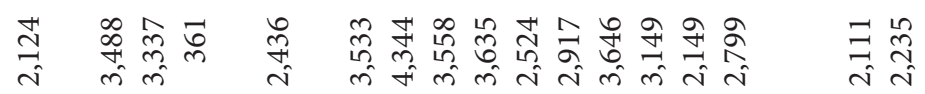

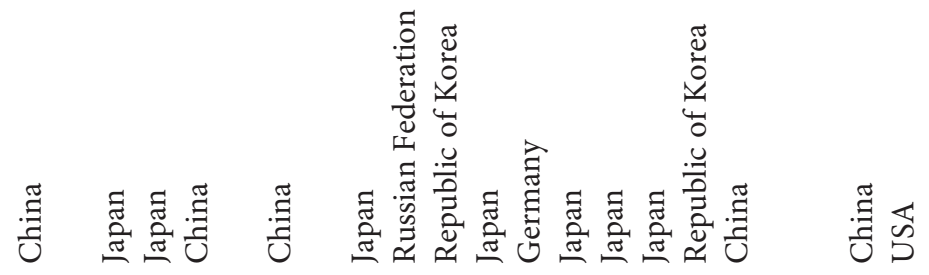

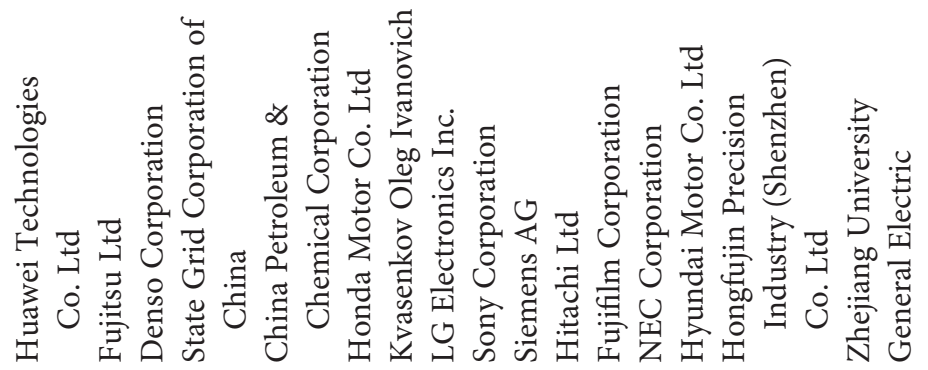




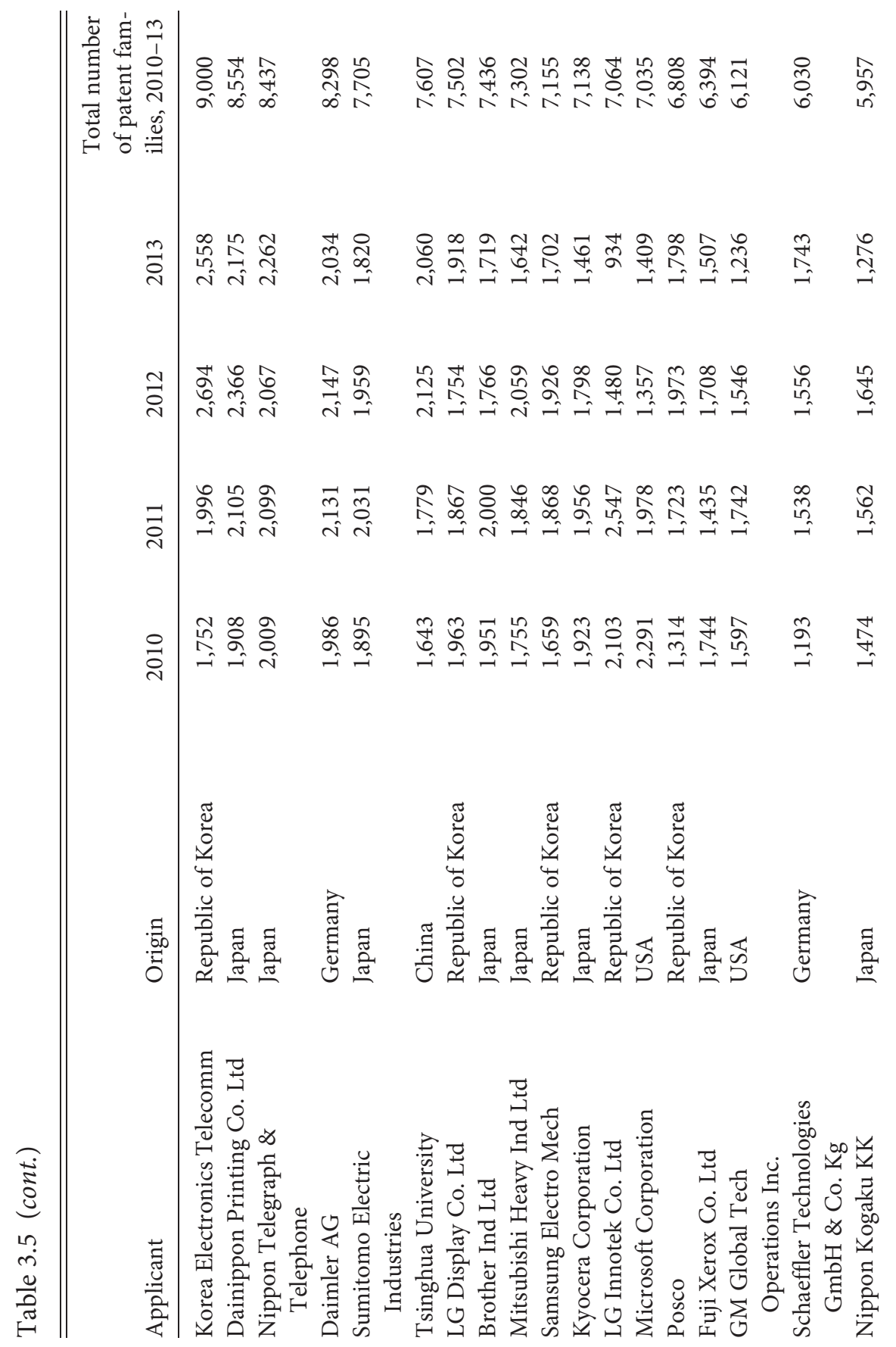




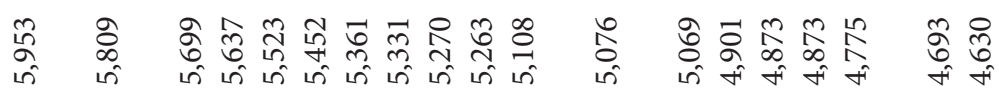

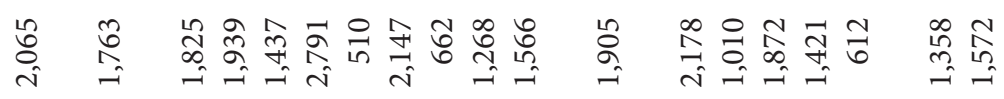

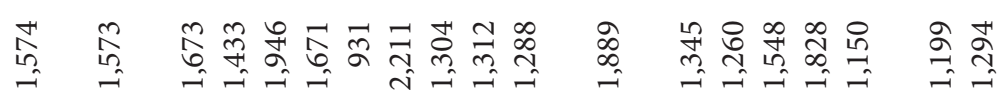

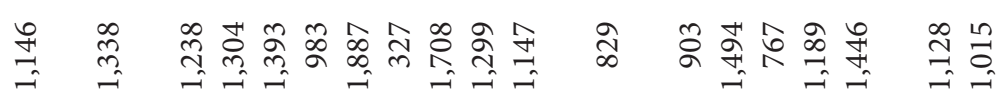

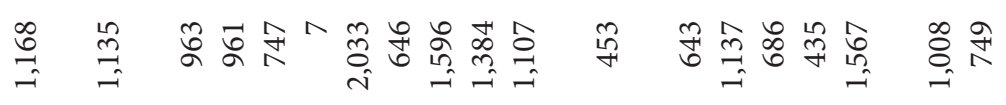
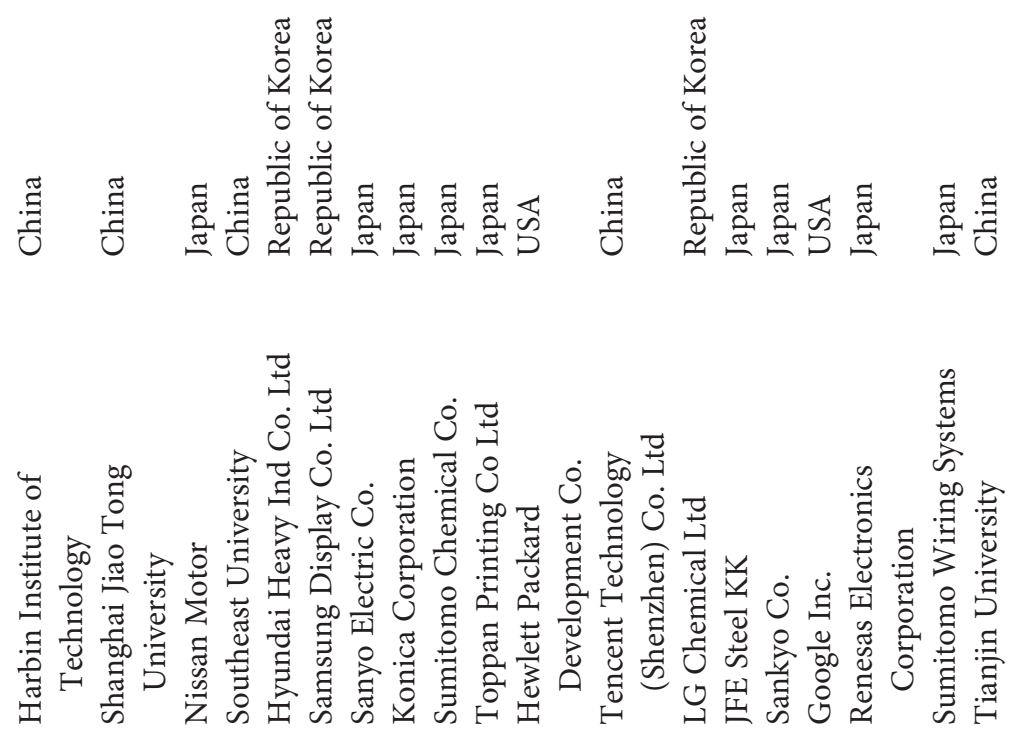


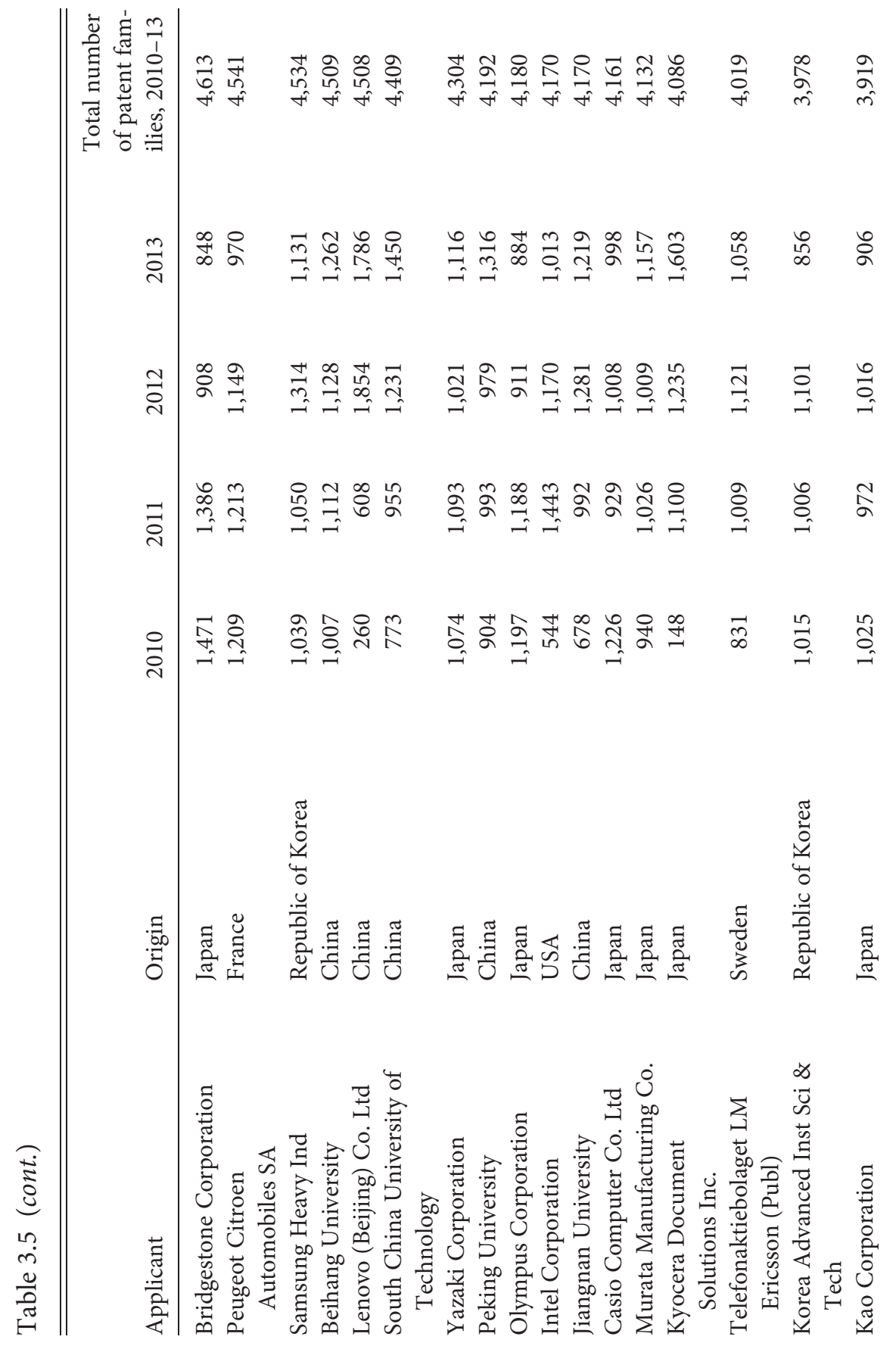




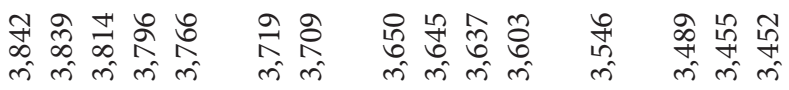

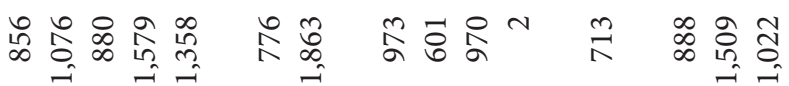

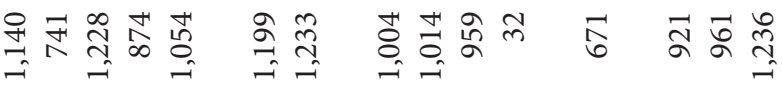

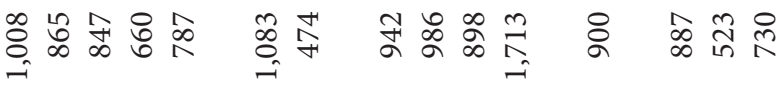

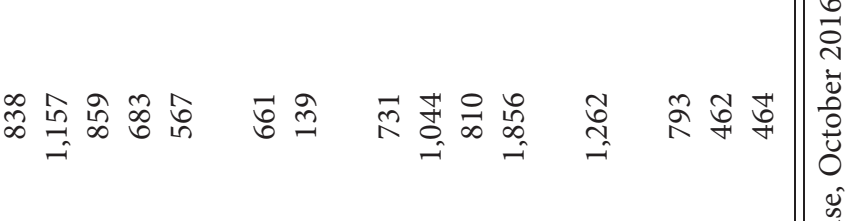

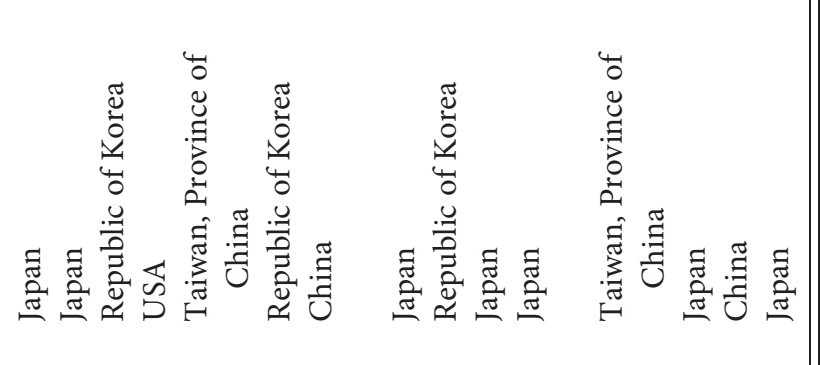

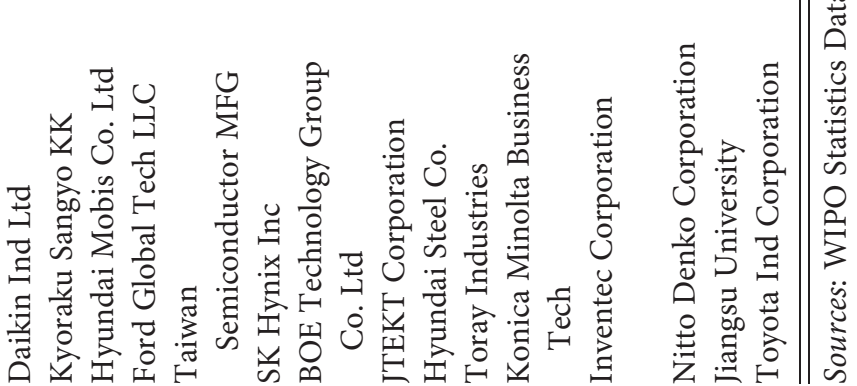


Combined, these thirteen applicants accounted for 8 percent of all patent families held by the top 100 applicants.

In 2010-13, the top three universities in patent families worldwide occupied positions thirty, thirty-seven, and fifty-one among the top applicants. These universities are Zhejiang University (9,488 patent families), Tsinghua University $(7,607)$ and Shanghai Jiao Tong University $(5,809)$. Two public research institutes took positions thirty-two and fifty: the Korea Electronics Telecomm $(9,000)$ and the Harbin Institute of Technology $(5,953)$.

Table 3.6 shows the top five university and public research institute applicants in patent families for selected origins in 2010-13. The top five university and public research institute applicants in China each created between 5,000 and 10,000 patent families during this four-year period. As shown in Table 3.5, all top five university and public research institute applicants from China are among the top 100 applicants in patent families worldwide.

Each of the top five university and public research institute applicants in the Republic of Korea had between about 2,000 and 9,000 patent families in 2010-13. Three university and public research institute applicants in Japan created more than a thousand patent families during 2010-13, while two public research institutes in France and one in Germany were also above the 1,000 mark.

The number of patent families created worldwide in 2013 was higher than that in 2010 for nineteen of the thirty university and public research institute applicants listed in Table 3.6, including all the top five for China and France. Compared to 2010, the number of patent families created in 2013 more than doubled for Southeast University of China, INSERM of France, and Northwestern University of the U.S.

\subsubsection{By IP Office}

In terms of the absolute number of nonresident university and public research institute patent applications, the top destinations over the past ten years have been the State Intellectual Property Office of China (SIPO), the United States Patent and Trademark Office (USPTO), the European Patent Office (EPO), the Japan Patent Office (JPO), the Canada Intellectual Property Office (CIPO), and the Korea Intellectual Property Office (KIPO) 


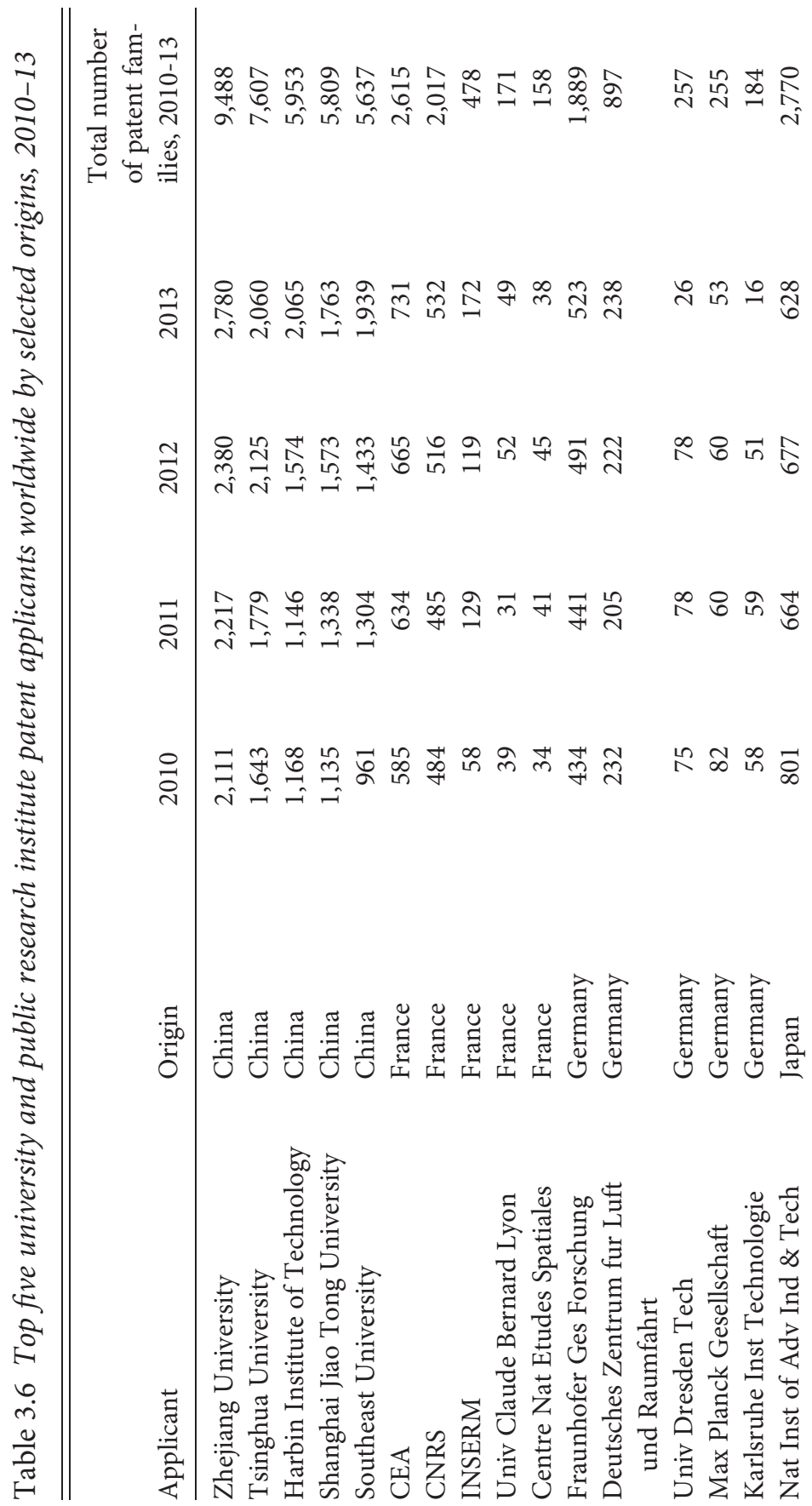




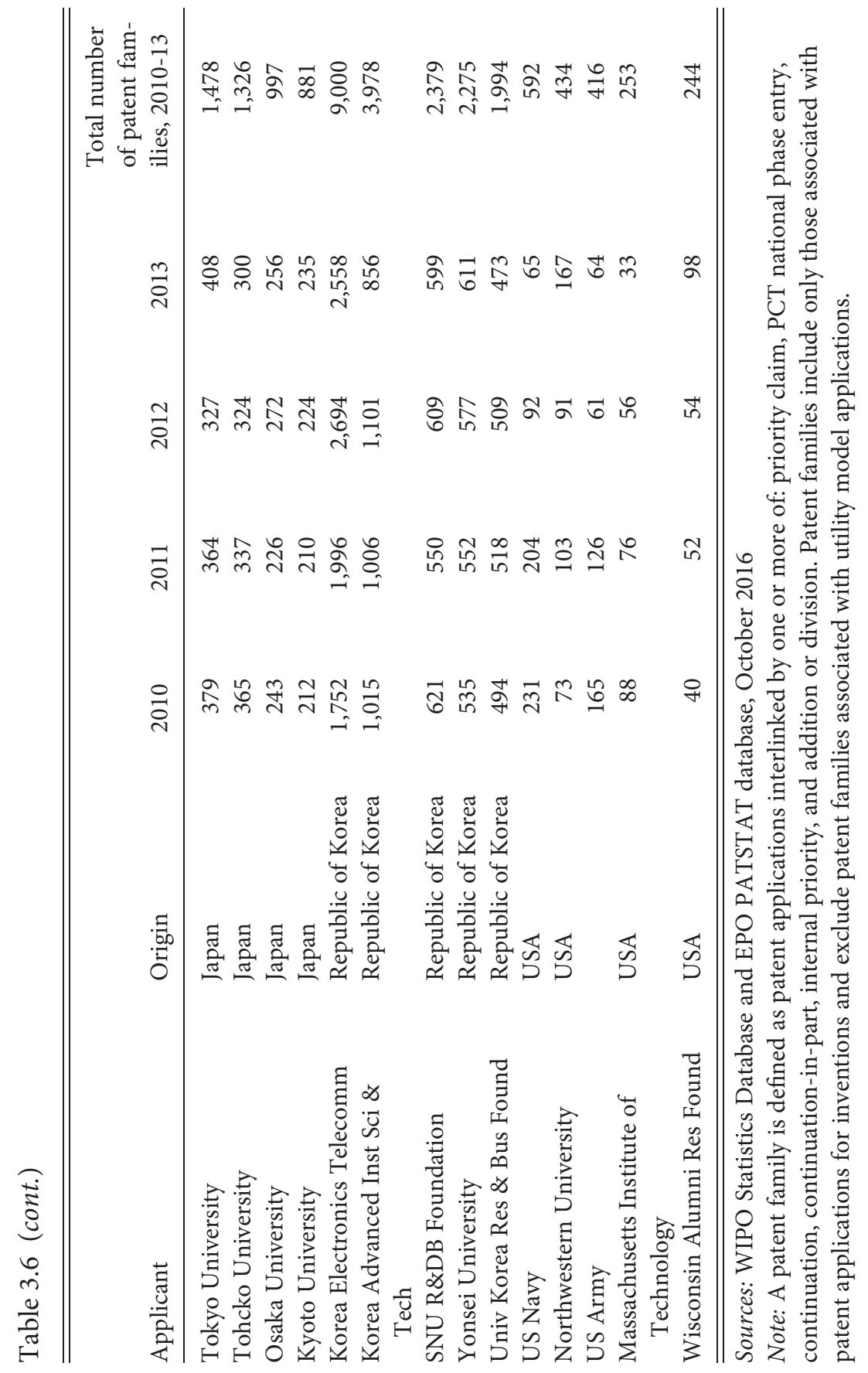




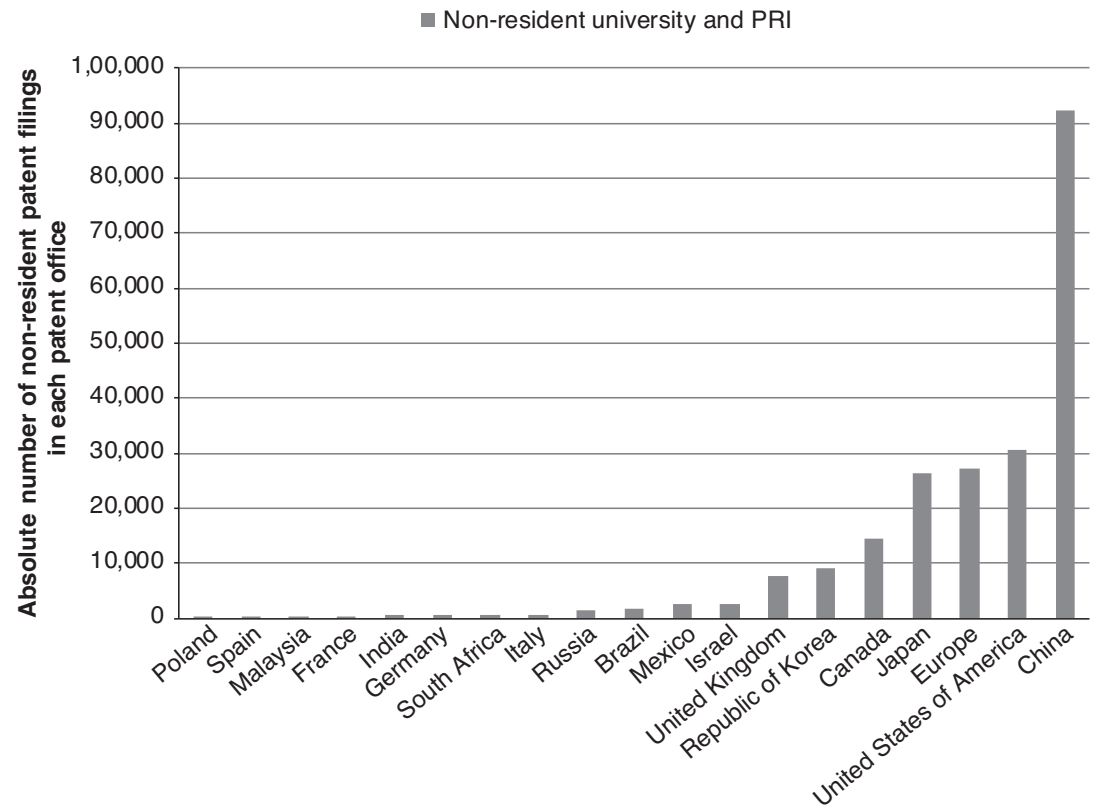

Figure 3.18 Nonresident university and public research institute patent applications for selected patent offices, 2006-15

Source: WIPO Statistics Database and EPO PATSTAT, January 2017

(Figure 3.18). ${ }^{14}$ Interestingly, the nonresident share of total university and public research institute patent applications is much higher at the JPO (58.6 percent), US PTO (54.0 percent), and EPO (49.5 percent) than at SIPO (13.1 percent) and KIPO (7.0 percent) (see Figure 3.19).

In the period 2006-15, the main sources of patent applications going outside a country were the U.S., France, Germany, the Republic of Korea, Japan, and China (Figure 3.20). However, the share of patent applications filed abroad by university and public research institute applicants was highest for the following countries of origin (Figure 3.21): Israel (90.9 percent), France (69.8 percent), the United Kingdom (66.1 percent), the U.S. (62.9 percent), Germany

${ }^{14}$ Data by office are broken down into resident applications (filed at the home office) and nonresident applications (filed by an applicant residing outside the jurisdiction of the office). 


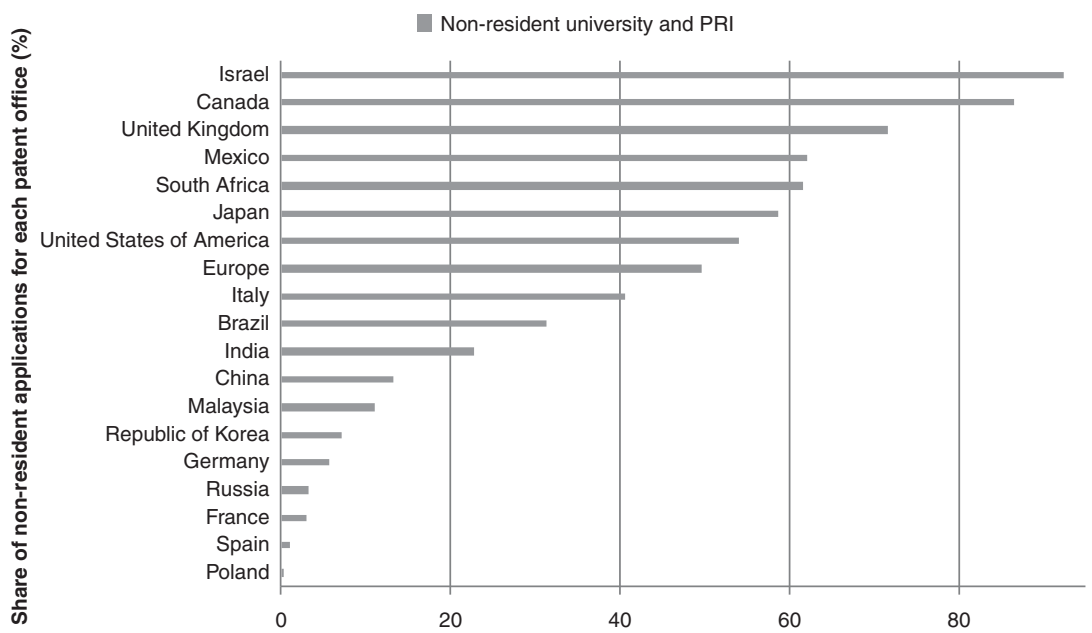

Figure 3.19 Share of nonresident university and public research institute patent applications for selected offices, 2006-15

Source: WIPO Statistics Database and EPO PATSTAT, January 2017

(61.7 percent), Canada (59.6 percent), Italy (57.5 percent), South Africa (56.3 percent), and India (46.1 percent).

\subsection{Conclusion}

In this chapter, we proposed a methodology for measuring academic patents. Using WIPO's PCT and the EPO's PATSTAT data, we provided a relatively comprehensive picture of global academic patenting data.

We showed that global patenting by public research institutes and universities has increased in the last thirty-five years and the map of the main actors has changed significantly. The main findings can be summarized as follows.

The main actors in global patenting are still private sector businesses, but university and public research institute applications are surging as important innovation drivers.

The biggest trend over the last thirty-five years has been a shift in university and public research institute patenting dominance from Europe and the U.S. to Asia. 


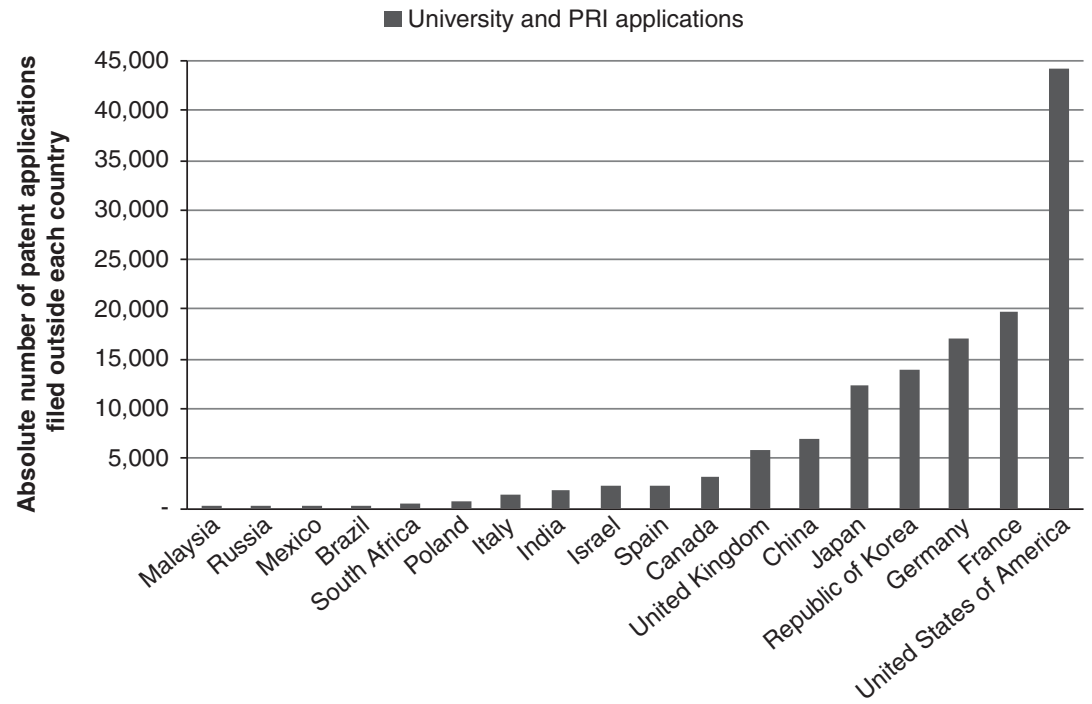

Figure 3.20 Patent applications filed abroad by universities and public research institutes for selected origins, 2006-15

Source: WIPO Statistics Database and EPO PATSTAT, January 2017

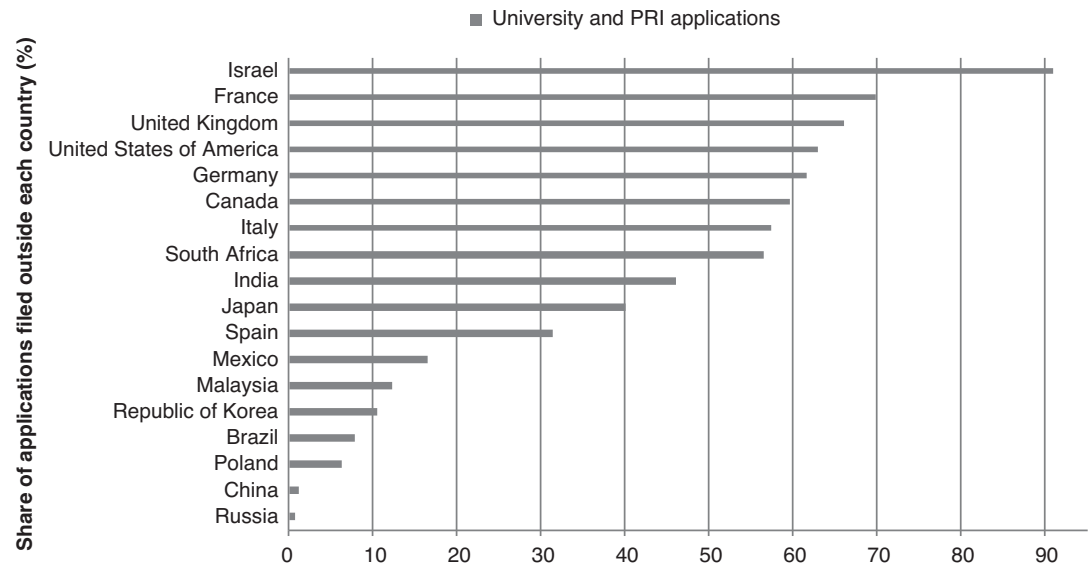

Figure 3.21 Share of patent applications filed abroad by type of applicant, selected origins, 2006-15

Source: WIPO Statistics Database and EPO PATSTAT, January 2017 
Applications by universities recorded in the PATSTAT and PCT databases were concentrated in science-based technology fields, especially pharmaceuticals and the biological sciences.

In the middle-income group of economies, universities hold more patents than public research institutes, while in the high-income group public research institutes tend to patent more than universities.

However, it is important to remember that there are numerous factors that can contribute to a university or public research institute's proclivity to patent. A strong focus on science, technology, engineering, and mathematics, public policies that govern IP ownership between university and industry, as well as other policies that enhance the use of patents are all likely to influence the patenting activities of universities and public research institutes across countries (Perkmann et al. 2013).

Nevertheless, while there are many limitations in using patent data and the extent to which it measures innovativeness, we contend that these data are useful in helping to identify potential weaknesses and highlight the strengths of universities and public research institutes.

\section{References}

Aldridge, T. T. and D. Audretsch (2011). "The Bayh-Dole Act and scientist entrepreneurship." Research Policy, 40(8), 1058-67.

Blumenthal, D., E. G. Campbell, M. S. Anderson, N. Causino, and K.S. Louis (1997). "Withholding research results in academic life science: Evidence from a national survey of faculty." Journal of the American Medical Association, 277(15), 1224-8.

Dernis, H. and M. Khan (2004). Triadic Patent Families Methodology. OECD Science, Technology and Industry Working Papers. Paris: Organisation for Economic Co-operation and Development.

Du Plessis, M., Van B. Looy, X. Song, and T. Magerman (2010). Data Production Methods for Harmonized Patent Statistics: Patentee Sector Allocation 2009. Brussels: Eurostat.

Geuna, A. (2001). "The changing rationale for university research funding: are there negative unintended consequences?" Journal of Economic Issues, 35, 607-32.

Geuna, A. and F. Rossi (2011). "Changes to university IPR regulations in Europe and the impact on academic patenting." Research Policy, 40(8), 1068-76.

Graff, G. D. (2007). "Echoes of Bayh-Dole? A survey of IP and technology transfer policies in emerging and developing economies." In A. Krattiger, R. T. Mahoney, L. Nelsen, J. A. Thomson, A. B. Bennett, K. Satyanarayana, G. D. Graff, C. Fernandez, and S. P. Kowalski, Intellectual Property Management 
in Health and Agricultural Innovation: A Handbook of Best Practices. Oxford: Oxford University Press.

Grimaldi, R., M. Kenney, D. S. Siegel, and M. Wright (2011). “30 years after Bayh-Dole: reassessing academic entrepreneurship." Research Policy, 40(8), 1045-57.

Guellec, D. and B. Van Pottelsberghe de la Potterie (2007). The Economics of the European Patent System: IP Policy for Innovation and Competition. Oxford: Oxford University Press.

Henderson, R., A. B. Jaffe, and M. Trajtenberg (1998). "Universities as a source of commercial technology: A detailed analysis of university patenting, 1965-1988." Review of Economics and Statistics, 80(1), 119-27.

Kelly, I. (2016). Patents for Technology Transfer: A Practical Guide. Seattle: CreateSpace Independent Publishing Platform.

Kenney, M. and D. Patton (2011). "Does inventor ownership encourage university research-derived entrepreneurship? A six university comparison.” Research Policy, 40(8), 1100-12.

Khan, M. and S. Wunsch-Vincent (2011). "Capturing innovation: The patent system.” In S. Dutta and I. Mia (eds.), The Global Information Technology Report 2010-2011. Geneva: World Economic Forum.

Martínez, C. (2011). "Patent families: When do different definitions really matter?" Scientometrics, 86, 39-63.

Mercelis, J., G. Galvez-Behar, and A. Guagnini (2017). “Commercializing science: Nineteenth- and twentieth-century academic scientists as consultants, patentees, and entrepreneurs." History and Technology, 33(1), 4-22.

Mowery, D. C., R. R. Nelson, B. N. Sampat, and A. Ziedonis (2004). Ivory Tower and Industrial Innovation: University-Industry Technology Transfer Before and After Bayh-Dole. Stanford: Stanford University Press.

Perkmann, M., V. Tartari, M. McKelvey et al. (2013). "Academic engagement and commercialisation: A review of the literature on university-industry relations." Research Policy, 42(2), 423-42.

Rosenberg, N. and E. Steinmueller (2013). "Engineering knowledge.” Industrial and Corporate Change, 22(5), 1129-58.

Rothaermel, F. T., S. D. Agung, and L. Jiang (2007). "University entrepreneurship: A taxonomy of the literature." Industrial and Corporate Change, 16(4), 691-791.

Schacht, W. H. (2006). The Bayh-Dole Act: Selected Issues in Patent Policy and the Commercialization of Technology. (CRS Reports RL32076). Washington: Congressional Research Service.

SCImago (2010). SIR World Report. SCIMAGO Institution Rankings. www .scimagoir.com.

So, A. D., B. N. Sampat, A. K. Rai et al. (2008). "Is Bayh-Dole good for developing countries? Lessons from the US experience.” PLoS Biol, 6(10), e262. 
Sterckx, S. (2011). "Patenting and licensing of university research: Promoting innovation or undermining academic values?" Science and Engineering Ethics, 17(1), 45-64.

Thursby, J. G., A. W. Fuller, and M. C. Thursby (2009). "US faculty patenting: Inside and outside the university." Research Policy, 38(1), 14-25.

Thursby, J. G. and M. C. Thursby (2011). "Has the Bayh-Dole act compromised basic research?" Research Policy, 40(8), 1077-83.

Van B. Looy, P. Landoni, J. Callaert, Van B. Pottelsberghe, E. Sapsalis, and K. Debackere (2011). "Entrepreneurial effectiveness of European universities: An empirical assessment of antecedents and trade-offs." Research Policy, 40(4), 553-64.

WIPO (2011). World Intellectual Property Report 2011: The Changing Face of Innovation and Intellectual Property. Geneva: World Intellectual Property Organization.

WIPO (2015). World Intellectual Property Report 2015: Breakthrough Innovation and Economic Growth. Geneva: World Intellectual Property Organization.

Wright, M., B. Clarysse, P. Mustar, and A. Lockett (2008). Academic Entrepreneurship in Europe. Cheltenham: Edward Elgar. 


\section{Annex: Verifying the Accuracy of WIPO University and Public Research Institute Applicant Names}

To verify the accuracy of our identification of university and public research institute patents, and going beyond the use of existing applicant information, our strategy involved a semi-automated process in two stages, web crawling and modeling.

Web crawlers, also known as spiders or robots, are programs that automatically download web pages. Different tools can be applied to the crawling method, such as SAS, R, and Python. The aim is to identify a series of category-related words for each applicant using the Baidu search and recommendation system. For universities, we used words such as "university," "college," and "universities" to identify organizations. For public research institutes, keywords used were "research" and "institute." For corporations, several synonyms were applied to the keywords.

The web-crawling stage involved four steps. First, according to the applicant's name, the programs generated a series of URLs to be sent to the Baidu search engine system. Second, the program inspected the source code of the result pages including a Baidu-generated recommendation list as a raw textual data set. Third, the program removed unwanted text, leaving a cleaner textual data set. Fourth, it extracted the keywords within the textual data set with Perl regular expression.

The modeling stage, in turn, involved a typical data-mining process with two steps. In the first step, also called the training phase, a learning algorithm used the training data to generate a classification model. In second step, that learned model was applied to the test samples to identify names that met the criteria and to increase the accuracy of our institutional classifications. An underlying assumption in that process was that the distribution of keywords for the training examples was identical to that for test examples.

All in all, this process helps to further fine-tune our patent categorizations and their corresponding institutional affiliations. This opens a new way of classifying organizations as compared to classical patent search strategies to identify university and public research institute patents in the literature.

Still, the approach does not necessarily generate perfect results: first, the classification algorithms may not be sufficiently sound and robust; second, the results generated are based on probability rather than on certain verifications. Given these risks, manual checking was undertaken to confirm the accuracy of the final results. 
